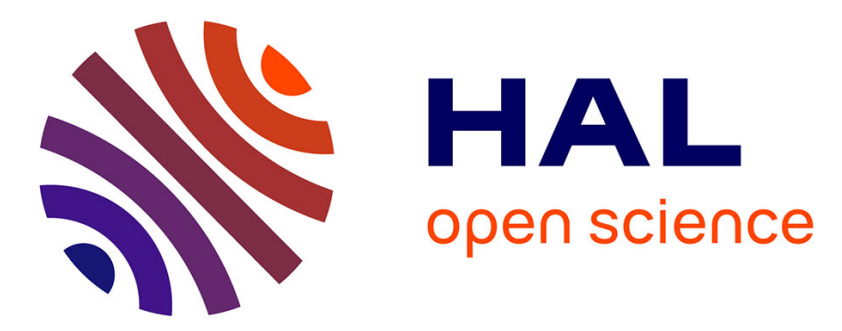

\title{
Effective ICT use for digital innovation: an actualized affordance perspective through ICT enabled design thinking
}

\author{
Anuragini Shirish, Shirish C. Srivastava, Imed Boughzala
}

\section{To cite this version:}

Anuragini Shirish, Shirish C. Srivastava, Imed Boughzala. Effective ICT use for digital innovation: an actualized affordance perspective through ICT enabled design thinking. Systèmes d'Information et Management, 2021, 26 (2), pp.7 -42. 10.3917/sim.212.0007 . hal-03184876

\author{
HAL Id: hal-03184876 \\ https://hal.science/hal-03184876
}

Submitted on 29 Mar 2021

HAL is a multi-disciplinary open access archive for the deposit and dissemination of scientific research documents, whether they are published or not. The documents may come from teaching and research institutions in France or abroad, or from public or private research centers.
L'archive ouverte pluridisciplinaire $\mathbf{H A L}$, est destinée au dépôt et à la diffusion de documents scientifiques de niveau recherche, publiés ou non, émanant des établissements d'enseignement et de recherche français ou étrangers, des laboratoires publics ou privés. 


\title{
Effective ICT use for Digital Innovation: An Actualized Affordance Perspective through ICT enabled Design Thinking
}

\author{
Anuragini Shirish* \\ Shirish C. Srivastava** \\ Imed Boughzala* \\ *Université Paris-Saclay, Univ Evry, IMT-BS, LITEM, 91025, Evry- \\ Courcouronnes, France \\ ** HEC Paris, 1 Rue de la Libération, 78351 Jouy en Josas Cedex, France
}

\begin{abstract}
Available technologies in organizations can be exploited for creating useful innovative solutions in a rather quick, efficient and economical way. Despite the huge benefits that can be derived by proactively exploiting available technologies and systems for innovation, there is relatively less academic research devoted to the subject. Motivated by this perceptible gap in the digital innovation literature, we theorize and examine the role of one possible structured creative mechanism (design thinking approach) for exploiting existing digital technologies to facilitate innovation. Grounding our arguments in the 'effective use of IS' and 'technology affordance' literature, we conceptualize innovation agent attributes and actualized innovation affordance achieved through the use of ICT, as the two salient facilitators for digital innovation. Innovation agent attributes are operationalized via domain generic and domain specific attributes of 'creative self-efficacy' and 'affect towards ICT use' and actualized innovation affordance is operationalized as the effective use of available technologies through an 'ICT enabled design-thinking approach'. The hypothesized model is empirically tested via a quasi-experimental method comprising data from a two-wave temporally separated survey. Results establish the significant influence of both - innovation agent attributes and actualized innovation affordance for facilitating digital innovation. Moreover, actualized innovation affordance, operationalized through ICT-DT, has a stronger association with digital innovation compared to the innovation agent attributes. This result underlines the need for organizations to proactively focus on using ICT effectively through structured creativity approaches (such as DT) for facilitating innovative outcomes. The study also offers several implications for research and practice.
\end{abstract}

\section{Keywords}

Design thinking, digital innovation, creative self-efficacy, affect towards ICT use, microfoundations, actualized affordances, effective use. 


\section{Utilisation efficace des TIC pour l'innovation digitale: Une perspective actualisée d'affordance à travers le Design Thinking supporté par les TIC}

\section{Résumé}

Les technologies de l'information (TIC) disponibles dans les organisations peuvent être utilisées pour créer des solutions innovantes d'une manière rapide, efficace et économique. Malgré la nécessité de mieux comprendre les modalités permettant d'utiliser les TIC dans les organisations pour favoriser l'innovation, la littérature sur l'innovation numérique/digitale se concentre principalement sur l'étude de la mise en œuvre de TIC existantes dans de nouveaux contextes ou sur la conception et le développement de nouvelles technologies de l'information. Cet article enrichit ces travaux de recherche en étudiant un mécanisme créatif alternatif mobilisant les technologies digitales existantes pour l'innovation. En ancrant nos arguments dans la littérature sur l'usage efficace des SI et «l'affordance de la technologie », nous conceptualisons les caractéristiques des agents d'innovation et l'affordance actualisée de l'innovation basée sur l'utilisation des TIC, comme les deux principaux facilitateurs de l'innovation digitale. Les caractéristiques des agents d'innovation sont opérationnalisées par le biais de caractéristiques génériques et spécifiques au domaine de «l'auto-efficacité créative » et de «l'affect envers l'utilisation des TIC ». L'affordance de l'innovation actualisée est opérationnalisée comme l'utilisation efficace des technologies disponibles grâce à une approche de conception basée sur les TIC ou encore «ICT enabled design-thinking » (ICT-DT). Le modèle proposé est testé empiriquement via une méthode quasi-expérimentale comprenant des données provenant d'une enquête en deux temps de collecte. Les résultats montrent une influence significative à la fois des caractéristiques de l'agent d'innovation et de l'affordance actualisée de l'innovation pour faciliter l'innovation digitale. Cependant, l'affordance actualisée de l'innovation, opérationnalisée par l'approche ICT-DT, a une relation plus forte avec l'innovation digitale par rapport aux caractéristiques de l'agent d'innovation. Cela souligne la nécessité pour les organisations d'intégrer l'utilisation des TIC pour permettre des approches de créativité structurées (telles que le DT) et encourager les productions innovantes. L'étude offre également plusieurs implications pour la recherche et pour la pratique.

\section{Mots clés}

Design thinking, Innovation numérique, auto-efficacité créative, affect envers l'usage des TIC, micro fondations, affordance actualisée, usage efficace

\section{Introduction}

Digital innovation, which pertains to the use of digital technologies for renewing and transforming business models, has been conceptualized in different ways in IS literature (Kohli and Melville, 2019). The three broad conceptualizations of digital innovation relate to - (1) adoption and diffusion of an existing IT artifact to a new context or organization (e.g. Fichman, 2004; Jeyaraj et al., 2006; Rahrovani et al., 2014), (2) design and development of new IT artifacts by combining physical and digital products (e.g. Lee and Berente, 2012; Yoo et al., 2010), and (3) creative application of existing IT artifacts within the organization by combining technological and organizational dimensions to create value (e.g. Fichman et al.,2014; Chatterjee, et al., 2020, Srivastava et al., 2015). Hence, digital innovation includes activities related to either the 'initiation, development, and implementation' of new systems, or the 'exploitation' of existing systems for innovative purposes.

Prior IS innovation literature has laid emphasis on the need for effectively using available resources for designing innovative solutions (Srivastava et al., 2013; Srivastava, et al., 2021, Srivastava and Shainesh, 2015). Evidently, to provide quick, efficient and economically viable 
innovative solutions, there is a need to examine how available technologies in organizations can be exploited and effectively used for creating such solutions. Kohli and Melville (2019) in their comprehensive literature review article on digital innovation have emphasized the need to examine the exploitation aspect of digital innovation i.e., reuse and recombination of technology and data for digital innovation orchestration. However, Kohli and Melville (2019) note that $91 \%$ of the reviewed digital innovation articles examine the development and implementation aspects of digital innovation, while only $9 \%$ of the articles study aspects related to initiation and exploitation of existing technologies for innovative outcomes. Given the importance of understanding the mechanisms for effectively using existing organizational technologies for innovation and the relatively less research attention given to the subject thus far, presents a glaring gap in the digital innovation literature. Moreover, the link between the strategic and pivotal role of available information technology within an organization in fostering digital innovation outcomes is inconsistently addressed in literature, with only one recent research leveraging the technology affordance lens addressing this crucial gap at the organizational level (Chatterjee, et al., 2020). Motivated by this perceptible void in the digital innovation and affordance literature, we theorize and examine one possible mechanism for exploiting existing digital technologies in the organization for innovation.

Exploitation of technologies for digital innovation implies leveraging existing IS for maximal value, such as reusing prevailing systems in new ways and for new purposes. Similar to recent study by Chatterjee et al., (2020), we view the exploitation of existing organizational technologies through the lens of 'effective use' and 'actualized affordance', which together offer a parsimonious framework for conceptualizing and examining digital innovation (BurtonJones and Grange 2013; Burton-Jones and Volkoff, 2017). Actualized affordance is the affordance enacted by the human agents through ICT tools as informational objects for the digital innovation (Livingston et al., 1997; Withagena \& Kampb, 2018; Ciriello et al., 2017; 2019), We posit that orchestrating 'effective use' of existing technologies in the organizations can help achieve innovation goals. Effective use of IS refers to the "use of systems for attaining the desired goals" (Burton-Jones and Grange 2013, p. 633) or "intelligent effort by direct users ... [such that] the effort facilitates desired outcomes" (LeRouge et al., 2007, p. 1291). In the context of our research, the term orchestration of digital innovation signifies the modalities for facilitating an effective use of IS for innovation. It refers to the problem-solution matching as a micro foundation of digital innovation and includes the instrumental role of digital technologies in enabling or supporting such orchestration, pursued by an innovation agent or by a collective (Nambisan et al., 2017, p227). For theorizing the mechanisms facilitating such a digital innovation, we need to build on the three basic elements of 'effective use' namely, characteristics of the task, the nature of systems and competencies and motivations of users (Burton-Jones and Straub 2006). In our study context, the 'task' relates to achieving innovation outcomes by exploiting the existing organizational digital 'systems' and leveraging the competencies of the 'users' or the organizational innovation agents. Thus, from the effective use perspective, the two elements for facilitating 'digital innovation outcomes' using technology are competent technology users or innovation agents and an actualized innovation affordance achieved through the effective use of available technologies (Burton-Jones and Volkoff 2017; Chatterjee et al., 2020). Appendix 1 provides a framework that shows how the concept of effective use and actualized information affordances are fused to enable us to effectively understand the role of technology exploitation for digital innovation orchestration in the context of this study.

Clearly, exploitation of existing systems presupposes two prerequisites: a goal directed agent with creative potential and an enactment of effective use of existing IS by the agent for fulfilling 
the desired goals, also termed as actualized affordance (Burton and Grange 2013). This is similar to the two factors of digital innovation described by prior literature -one that leans towards recruiting and building 'technology users with appropriate innovative capabilities and motivations', and the other, that focuses on implementing the 'right methods for orchestrating innovation' (Amabile and Pratt, 2016; Drazin et al., 1999; Srivastava et al., 2013; Srivastava, 2015). Recent practitioner reports also reiterate the key roles of employee competency and structured innovation methods for effectuating digital innovation (Forrester, 2019, Gartner, 2019). Though, digital innovation literature has examined each of these elements in different contexts, efforts to understand their relative importance for the enactment of digital innovation, especially at the individual level of analysis is largely missing (Ciriello and Richter, 2015; Chatterjee et al., 2020; Fichman et al., 2014; Micheli et al., 2019), which we try to address through our study.

In a recent study, organizational courage is conceptualized as a collective and primodial attribute of human agency that percolates into how creativity and innovation goals are approached in a digital innovation context (Chatterjee et al., 2020). The article found that organizational courage and harmonized IT affordance in an organization (HITA) offered a matching fit enabling actualization of the technology affordances for digital innovation outcomes (Chatterjee et al., 2020). HITA is reflected as a co-alignment of the three major IT affordances in an organization - collaborative affordance, organizational memory affordance, and process management affordance. Extending this line of enquiry, in our study, we conceptualize the innovation agent competencies and motivations, as the agent attributes that are expected to assist in the task of innovation. Because we are examining the context of digital innovation at the micro level, we consider two proximal attributes: 'innovation agent attributes', one that relates to the ability to innovate (domain generic) and the other that relates to the use of ICT itself (domain specific). The domain generic competency that we consider in our study is the innovation agent's creative self-efficacy, which is related to the human agent's cognitive creative competency, and the domain specific attribute for digital innovation that we examine in our study is the innovation agent's affect towards ICT use, which describes the human agent's affective disposition towards the use of ICT for digital innovation. These two factors are intrapersonal in nature and reside within the cognitive and affective spheres of the innovative agent —waiting to be appropriated (Amabile, 1996). Both these agent attributes have been identified as significant attributes in the creativity and innovation (creative self-efficacy) (Amabile, 1996) and information systems (IS) - (affect towards ICT use) (Thompson et al., 1991) literature, but have not yet been examined in the context of digital innovation.

The actualized innovation affordance, is conceptualized in our study through one specific method, namely - ICT enabled design-thinking (DT) approach. Past management research provides consistent evidence that DT approach helps in fostering innovation and is beneficial for firms adopting it (e.g., Brown \& Martin, 2015; Cooper et al., 2009; Gruber et al., 2015; Rauth et al., 2014). Currently, design-thinking approach is considered as one of the effective structured creative methods (Johansson-Sköldberg et al., 2013; Glenn et al., 2014; Pope-Ruark et al., 2019) and we posit that it is equally applicable to the context of digital innovation (Elsbach and Stigliani, 2018; Micheli et al., 2019). A design index conceived as early as 2015 showed that for a period of 10 years in a row, design-led companies have maintained significant stock market advantage, outperforming its competitors by a whopping $211 \%$, making design as an important creative process to instill for organizational success (DDM, 2020). However, the basis of DT largely continues to be a human-process-centric activity, which may or may not use ICTs. Digital innovation researchers have stressed the key-role of ICTs for effectuating a structured creative innovation method (Ciriello \& Richter, 2015; Srivastava \& Shainesh, 2015; 
Mithas et al., 2016). Though it is generally recognized that ICT use enhances the creative processes (e.g., Couger et al., 1993; Pacauskas \& Rajala, 2017), technology enabled design thinking has thus far has neither been operationalized nor empirically validated in academic research. We address this void by conceptualizing ICT enabled design-thinking (ICT-DT) approach to operationalize the 'actualized innovation affordance' for facilitating digital innovation. More details on why we look at ICT-DT in this research is also elaborated in subsequent section (see, section 2.2 below). Building on the discussion above, the research question that we seek to address in our study is:

RQ: Do 'innovation agent attributes' and 'actualized innovation affordance' help in exploiting existing IS to facilitate digital innovation? And what is their relative importance?

The answer to this question is germane to understanding how digital innovation can be facilitated in an organizational setting by orchestrating the effective use of existing IS. Theoretically, we aim to integrate digital innovation and effective use of IS literature to examine the rather unexplored 'exploitation' of available technologies perspective for digital innovation. For theoretical coherence and parsimony, in the context of this paper, we use the termactualized affordance to signify the enactment of effective use of available generic ICT that are easily accessible for creative process by a goal directed innovation agent for facilitating innovation. Rooted in the logic of technology affordances (Majchrzak and Markus, 2012; Pozzi et al., 2014; Godé et al., 2020; Boukef and Charki, 2019), our study leverages information systems (IS) and creativity literature to theorize the distinct influence of the two contextual dimensions on digital innovation (Nambisan et al., 2017).

To answer our research question, we employ a quasi-experimental method. The research data is collected through a two-wave temporally separated survey in a natural academic setting, where the respondents were expected to produce an innovative outcome by using the available ICT tools for collaboration and working. The academic context encouraged the study participants to exploit the existing IS through the use of the design thinking approach for solving an unstructured societal problem, which provided them with the opportunity to creatively undertake individual level digital innovation initiatives (Unsworth 2011; Kohli and Melville, 2019).

The rest of the paper is organized as follows. First, we provide background literature on the key concepts used in our study. Next, we elaborate on the theoretical arguments leading to the research model and hypotheses. Subsequently, we describe the details of the quasi-experimental method designed for validating the hypothesized model. Finally, after discussing the obtained results, we conclude with the theoretical and practical implications emerging from our study.

\section{Background Literature}

\subsection{Digital Innovation and Effective ICT Use}

Digital innovation is at the heart of today's economy. Organizations, nations, and societies are leveraging digital capabilities and technologies to stimulate and create value for different stakeholder groups through innovation either in underlying processes or the resulting products (Nambisan et al., 2017). Though, businesses and societies have realized the importance of digital innovations (Fichman et al., 2014; Yoo et al., 2012), theoretical deliberations devoted to understanding the modalities for 'proactively' fostering such innovations are limited (Livingston et al., 1997; Nambisan et al., 2017; Ciriello \& Richter, 2015). Research that focuses 
on theorizing and examining the mechanisms facilitating digital innovation will be of value to both theory and practice.

Although digital innovation has been described in the literature in different ways, in our research we examine how organizations can achieve digital innovation by exploiting existing organizational resources and technologies (Kohli and Melville, 2019). Specifically, taking an "effective use" of technology perspective, we posit that for achieving the task of digital innovation, organizations need to leverage the motivations and competencies of the users and orchestrate the use of organizational systems and technologies through a structured innovation approach (Burton-Jones and Grange 2013; Burton-Jones and Volkoff, 2017). We classify these two elements for facilitating digital innovation as 'innovation agent attributes' and 'actualized innovation affordance' (Livingston et al., 1997; Withagena and Kampb, 2018; Ciriello et al., 2017).

Traditionally, innovation has been linked to the creative ability of the individuals involved in the innovative process. Such innovation agent abilities have been shown to transcend their general attributes such as intelligence or personality traits to include domain and task specific attributes, which have been shown to influence innovation outcomes (Lubart, 2008; Lubart and Guignard, 2004). Recent literature on individual level creativity support systems also calls for further studies to tease out the relevant individual level attributes in the context of technology mediated creative process enactments (Wang and Nickerson, 2017). Thus, creative competencies and motivation to use technologies can be considered as important attributes to facilitate digital innovation.

In addition to recognizing the key role of 'innovation agent attributes', digital innovation researchers have also pointed to the key role of structured creativity innovation methods enabled by ICTs (Ciriello et al., 2017). For example, studies have investigated the role of creativity support systems in enhancing the level of innovation by stimulating and documenting creative processes (Massetti, 1996; Wierenga and van Bruggen, 1998; Wang and Nickerson, 2017; Couger et al., 1993; Pacauskas and Rajala 2017; Gabriel et al., 2016). Creativity, a quintessential concept related to innovation is defined as the process of forming novel, useful, and appropriate ideas (Amabile, 1983; Woodman et al., 1993). The terms creativity and innovation are often viewed as a single competency, but creativity is at the heart of all digital innovation research (Fichman et al., 2014). Consequently, in our study, we view creativity and digital innovation together as a sociotechnical phenomenon (Ciriello et al., 2015).

Prior studies focusing on the use of technologies for digital innovation have examined different technological aspects, for example - specific technology design features that can contribute to accidental innovation (Austin et al., 2012), the role of digital infrastructure in fostering innovation networks within organizations (Lyytinen et al., 2016; Ciriello \& Richard, 2015), or the competing concerns related to implementation of digital innovations (Svahn et al., 2017). As highlighted earlier, the bulk of the digital innovation literature focuses on the "development and implementation" aspects of digital innovation. Studies related to the "initiation and exploitation" of existing technologies for innovative outcomes are very limited (Kohli and Melville, 2019). By focusing on ways to exploit existing organizational technologies by using them more effectively we address a noteworthy gap in literature. Moreover, most digital innovation studies are in the form of conceptual frameworks, essays and reviews without empirical validation (Yoo et al., 2012; Fichman et al., 2014; Lusch and Nambisan, 2015; Kohli and Melville, 2019). There have also been calls in this domain to deliberate on the sociomateriality perspective for examining micro-foundations to digital innovation orchestration 
(Barrett et al., 2012; Nambisan et al., 2017) by adopting an affordance perspective for examining digital innovation (Chan et al., 2019). Few studies such as Ciriello et al. (2017), have followed this line of enquiry to conceptualize four interrelated collective digital innovation practices in corporate settings, namely making sense of an idea, aligning mental models, negotiating solution paths, and crafting an idea. We build on such prior studies by taking into account the use of specific innovation processes and affordances offered by the digital artefacts (Chatterjee et al., 2020). In our study, by leveraging the effective use and affordance perspective we clearly delineate the role of user attributes (innovation agent attributes) and a structured innovation approach through effective technology use (actualized innovation affordance) in the form of ICT enabled design thinking (ICT-DT) for facilitating digital innovation. We describe the conceptualization of actualized affordance of existing organizational technologies through ICT-DT in the next section.

\subsection{ICT enabled Design Thinking - An Actualized Innovation Affordance Approach}

Among the various structured innovation processes, the design-thinking (DT) approach has recently gained wide popularity amongst innovation practitioners and is considered to be one of the effective innovation and creativity methods (Johansson-Sköldberg et al., 2013; Glen et al., 2014; Elsbach and Stigliani, 2018). DT is a human-centric approach widely used to stimulate creativity relevant processes during innovation management (Gartner, 2019; Von Stamm, 2008; Mahmoud-Jouini et al., 2019). Recent research on the subject has demonstrated the positive impact of the DT approach on innovation (Carlgren et al., 2016; Elsbach and Stigliani, 2018; Liedtka, 2017; Nagaraj et al., 2020) and the consequent financial outcomes (Forrester, 2019, Gartner, 2019). Following digital innovation researchers who have stressed on the key role of ICTs for effectuating a structured creative innovation process (Ciriello and Richter, 2015; Srivastava and Shainesh, 2015; Mithas et al., 2016) we conceptualize actualized innovation affordance through "ICT enabled design thinking process" (ICT-DT). Please note that ICT-DT is one of the possible approaches that can be leveraged for actualized innovation affordance, there can also be other methods, which future research can explore and examine.

Specifically, given the embedded nature of the DT approach, we conceptualize ICT-DT as an actualized innovation affordance for effective use of technology by the human agents trying to use existing IS for their desired innovation goals (Burton and Volkoff, 2018). DT approach is particularly interesting from the standpoint of this research for two specific reasons. First, for its popularity and relevance to the innovation management discipline. Second, the context of the specific study, which was undertaken in a natural field setting that recommended the use of DT for enacting the creativity processes through technology - which is consistent with our objective of using ICT for DT. In other words, the desired structured creativity process (DT) was infused into the context of the study a priori (Dumas and Mintzberg, 1989, 1991). Hence, in our study we contextualize the DT approach to the digital innovation context through the use of existing ICT tools for effectuating DT approach. We term this contextualized DT approach as ICT enabled DT creative method (ICT-DT). Our conceptualization of ICT-DT is depicted through the use of ICT for the sequence of five activities or phases crucial to the design thinking approach -(1) empathize - data collection about the problem, (2) define - data synthesis to gain a refined understanding of the problem, (3) ideate - suggest ideas for solving the problem, (4) prototype - develop tangible representations of the ideas for solving the problem, and (5) test the problem solution with the potential users (see Plattner et al., 2009).

Although in our research we examine the use of general ICTs for effectuating DT method, prior research has also identified specific tools that might be suitable for each of the DT phases (Alves 
et al. 2013; Chasanidou et al. 2015). For example, Smaply, a web service that hosts and presents personas and other tools, such as stakeholder maps are useful for the empathize phase in the DT approach. Similarly, for the define phase in the DT approach, customer journey maps can be produced by tools such as Touchpoint Dashboard or Creately which generates service blueprints. For the ideate phase Strategyzer is a tool that can possibly be used. For the prototype phase Axure RP can perhaps be leveraged as it allows for rapid prototyping and helps get feedback through easy website creation techniques using a graphical user interface (Chasanidou et al. 2015). Several commercial firms are promoting all-purpose crowd thinking tools to practice design thinking. For example, some firms in France use a collaborative platform called Foreseeds for practicing the design thinking creative approach. Apart from the aforementioned specific tools, we know that existing IS can also be used during ideation and developmental phases of design thinking, such as PLM web conferencing is known to help in managing realtime problem-solving situations when developing new products by enhancing knowledge transfer amongst diverse participants (Merminod and Rowe, 2012). Technology innovation projects that combine design thinking and other agile methods are now commonly taught in business schools and students are encouraged to rely on generic ICT tools at their disposal for such projects (Freitas da Silva, 2020), which is similar to the approach followed in our research.

\section{Theory and Hypotheses}

\subsection{Linking innovation agent attributes with digital innovation}

In our research, we conceptualize the innovation agent competencies and motivations, as the agent attributes that are expected to assist in the task of innovation. Because we are examining the context of digital innovation, we consider two 'innovation agent attributes', one related to the ability to innovate (domain generic) and the other related to the use of ICT itself (domain specific). The domain generic competency that we consider in our study is the innovation agent's creative self-efficacy (Amabile, 1996), which is related to the human agent's cognitive creative competency, and the domain specific attribute for digital innovation that we consider in our study is the innovation agent's affect towards ICT use (Thompson et al., 1991), which describes the human agent's affective disposition towards the use of ICT for digital innovation.

Creativity theorists have flagged the importance of examining agent's self-perceptions about their own creative behaviors and capabilities (e.g., Tierney and Farmer 2011; Zhang, 2013). Past literature on creativity has emphasized the need to examine the individual's capabilities in orchestrating creative processes and behaviors (Bandura, 1977). It has also indicated the key role of self-efficacy in processes involving self-regulation (Bandura 1977; Bandura 1982). Moreover, domain specific self-efficacy has been found to have a stronger influence on the outcomes as opposed to a general self-efficacy measure (Choi, 2004; Malik et al., 2015). Consequently, in our research we theorize the key role of 'creative self-efficacy'. Tierney \& Farmer $(2002 ; 1999)$ observed that creative self-efficacy is a significant predictor of an individual's creative performance. Creative self-efficacy is the belief in one-self that the individual has the requisite knowledge and skills to produce creative outcomes. Prior research has found it to be a key driver for individual creativity (Gong et al., 2009; Lim \& Choi, 2009) and creativity is an essential component of digital innovation (Fichman et al., 2014; Micheli et al., 2019).

In our research, we focus on the exploitation of available ICT tools for achieving the desired innovation goals. We posit that when individuals are faced with a task, they will be motivated to use the available technologies to achieve their goals. However, this is contingent on the 
individuals having the efficacy to execute the assigned task. Past research shows that new idea generation leads to uncertainties, such uncertainties can be overcome when the individual has self-efficacy perceptions as these lead to safety perceptions which then are translated to innovation outcomes (Farr and Ford, 1990, Frese, et al., 1999). Individuals with past experience and motivation combine knowledge diversity more effectively which makes their task output more innovative in terms of both novelty and usefulness (Taylor and Greve, 2006). Creative self-efficacy has also been linked to development and implantation of ideas in organizational settings. (Hammond, et al., 2011). Because we are focusing on creative tasks, we argue that the individual's creative self-efficacy will play a salient role for the enactment of digital innovation through the effective use of available technologies (Burton and Volkoff, 2018; Kohli and Melville, 2019). Hence, grounding our arguments in prior creativity and effective IS use literature we posit that the individual's creative self-efficacy should be positively related to the facilitation of digital innovation. Hence, we hypothesize:

H1a: Innovation agent's 'creative self-efficacy' is positively associated with digital innovation.

Affect towards technology use has been identified as one of the ICT domain specific attributes of the individuals and is expected to positively impact digital innovations (Lubart \& Guignard, 2004). Prior studies have found that affect, in general, guides congruent behavioral responses (Koenig-Lewis \& Palmer, 2014; Kubicek et al., 2013; Richard et al., 1996). Behavioral affective association model predicts that affective associations influence not only the cognitive beliefs and behavioral responses of the individuals, but also impact an individual's final decisions and outcomes (Kiviniemi and Duangdao, 2009). Prior IS research views affect as one of the key dimensions responsible for shaping an individual's attitude towards technology use (Srivastava and Teo, 2021; Shirish, 2020). Moreover, 'affect towards ICT use' has been found to be a significant individual-level attribute that determines the extent of technology use (Thompson et al., 1991).

Notwithstanding the positive association of affect towards ICT use with task oriented digital outcomes, prior creativity research has shown a mixed impact of positive and negative moods on creative outcomes. For example, George and Zhou (2002) and George and Zhou (2007) demonstrate that negative mood, under certain circumstances, can lead to an increased creative performance. Another study from Bledow et al. (2011) shows that when there is an affective shift from a negative mood to positive mood, the creative performance increases. Hence, the relationship of an individual's mood with creativity is not conclusive. Moreover, mood and affect reflect different aspects of the emotional dimension. While affect is associated with a specific stimulus and usually determines an individual's attitude towards that stimulus (Thompson et al., 2001), mood is a superficial and transient emotional aspect of an individual and is not associated with a specific stimulus. Mood can manifest as a general affective state of an individual. Moreover, in our study we are examining the affect towards using technology.

Although, our task context depends on creativity, we argue that there is a positive relationship between positive affect towards ICTs with digital innovation. Our reasoning derives from the fact that ICT use in our context is contingent on effective mobilization of technological resources, which is similar to the instrumental use of technology. Hence, consistent with prior IS research a net positive affect towards ICT use should result in better mobilization of technological resources for the specific task situation of digital innovation (Shirish, 2020). We take the originally conceived view in IS research that 'affect towards ICT use' is more of a stable disposition of an individual towards technology use, accounting for the net of the positive 
and negative affect that individuals have towards technology (Thompson et al., 2001). Moreover, we are examining the specific context of effective technology use for digital innovation orchestration by goal directed innovative agents (Burton and Grange 2008; Diliello et al., 2011). Thus, based on prior studies, we argue that an innovation agent's affective disposition towards technology use is related to his/her task related motivational mechanisms, which in turn should facilitate digital innovation (Costa et al., 2017; Ashkanasy and Dorris, 2017; Ford, 1996; George and Zhou, 2002; George and Zhou, 2007). Hence, we hypothesize:

H1b: Innovation agent's 'affect towards ICT use' is positively associated with digital innovation.

\subsection{Linking actualized innovation affordance with digital innovation}

Technology affordance refers to "an action potential, that is, to what an individual or organization with a particular purpose can do with a technology or information system" (Majchrzak \& Markus 2012, pp. 832). However, it is through the effective use of the technology that one can explicate in a contextual manner the usefulness of technology affordance (Burton and Grange 2008). Prior research has shown that the mangling of creatively structured processes with technology through reciprocal and emergent intertwining of human and technical practices can influence digital innovation (Pickering, 2010). Because innovation affordance has been proposed as a useful lens for examining digital innovations in action (Orlikowski, 2007; Barrett et al., 2012; Nambisan et al., 2017; Ciriello et al., 2017; Burton and Volkoff, 2018), we argue that the actualized affordance offered by structured ICT-enabled innovation methods should facilitate digital innovation. However, we elaborate on the notion of actualized innovation affordance at the individual level in the context of our research.

In our study, innovation affordance is operationalized through the affordance of informational objects by innovative agents. It can also be the use of innovation practices enacted through technology use (Ciriello et al., 2017). Particularly, 'actualized innovation affordance' is a relational concept that links specific creativity approach, goal-oriented users, and ICTs as informational objects (Andriani and Cattani, 2016; Burton and Grange 2008). Thus, information objects (systems) interact with the goal-oriented user (innovation agent) to contribute to the enactment of affordance in the digital innovation context (Chan et al., 2019). This is similar to conception of business process model as an informational object in recent IS affordance studies (Bernhard et al., 2013). Use of ICT during the creativity process can extend the conceptual creative space for the innovation agents by enabling enhanced perspective taking and improved creative learning, which can facilitate enhanced digital innovation (Glăveanu et al., 2019). Hence, in the context of our research, ICT-DT that measures the actualized affordance is linked to digital innovation (Liedtka, 2017; Pope-Ruark et al., 2019) through the concept of effective IS use (Burton and Grange 2008).

We further tease out how ICTs could be used for creativity process engagement and why imbrication of user and systems is key for digital innovation (Bhurkhardt and Lubart, 2010; Livingstone et al., 1997). ICT serves as an institutional support mechanism for creative process engagement (Lubart, 2005). However, according to the ecological account of creativity, it is the actualized affordance that leads to materialization of creativity as well as technology induced creative process engagements (Pozzi et al., 2014). The exploitation of technology-enabled support for creative process available in the environment by an innovating agent thus becomes desirable (Livingstone et al., 1997; Isaksen et al., 1993). 
However, we must not ignore the possibility that ICTs can also constrain an innovation agent's activity (Leonardi, 2011). Prior research has shown the deleterious effects of rigid structured processes on creativity and exploration (Lenfle, 2008; Lenfle and Loch, 2010). Nevertheless, from the effective use perspective, we posit that the flexible and iterative nature of the ICT-DT method would provide individuals with an enabling environment for a goal directed innovation task (Burton and Volkoff, 2018). Prior research such as Lubart (2005) describes the key role of digital technologies in facilitating creative work through various mechanisms such as enhancing the communication between individuals, collaborating on creative projects, using creativity enhancement techniques, and integrating human-computer interactions during the idea production stage. The presence of and encouragement for unrestricted use of ICTs should lead to open and flexible innovation affordances by supporting the convergence of ideas and allowing for generative experimentation. Consistent with the findings of Lubart (2005), we posit that available ICTs, when effectively used through the DT approach, would facilitate innovation by providing the required structural support during the different phases of the DT method.

ICTs can also afford a viable foundation to understand the potential problems of users in depth by permitting easy collection of user data. Moreover, ICTs can also facilitate efficient data synthesis and analysis, which is clearly superior to the manual processes. Thus, ICTs can help innovation agents to better empathize and define the problem that requires an innovative solution. In a similar vein, ICTs can also be useful during the testing phase of design thinking for obtaining user feedback and also for capturing the digital usage footprints of the innovation agents. This information can be used to tweak the innovative process for better results. ICTs also afford better creative communication management amongst the innovation agents involved in the project (Lubart, 2005), which we believe is crucial for defining and ideating about the intended digital innovation. Defining and ideating stages of the design thinking process require close collaboration, wherein ICTs can complement face-to-face communication. Moreover, in the case of digital innovation, the innovation agents may also see affordances while using ICTs to express their creative acts through integrated human-computer cooperation during idea production (Lubart, 2005). In addition, available ICTs will also allow for implicitly representing and manipulating ideas; such an affordance is useful during the ideation and prototyping phases of design thinking. The use of ICTs for creative process would allow the innovation agent to appropriate both the convergent and generative affordances for digital innovation enactment (Yoo et al., 2012; Glăveanu et al., 2019). In summary, structured creative approach can positively influence innovation as it aids in the planning and the execution of innovations (see Osburn and Mumford 2006; Amabile 1983; Parnes and Noller, 1972; Sternberg, 1986).

Efficacious innovative agents would seek out opportunities and resources available in the social context/space to further their goals and aspirations (Bandura, 2001; Overmyer and Carlsen, 2019). Therefore, ICT use in the structured method of DT should clearly increase innovation agent's control over the execution of the creative process, which in turn will facilitate digital innovations. Hence, we contend that actualized innovation affordance enacted through ICT-DT by a goal directed motivated innovation agent in the context of a creative task should be positively related to digital innovation affordance (Burton and Grange 2008). We hypothesize:

H2: Actualized innovation affordance orchestrated through 'ICT enabled designthinking' approach (ICT-DT) is positively associated with digital innovation.

The hypothesized relationships are represented in Figure 1 


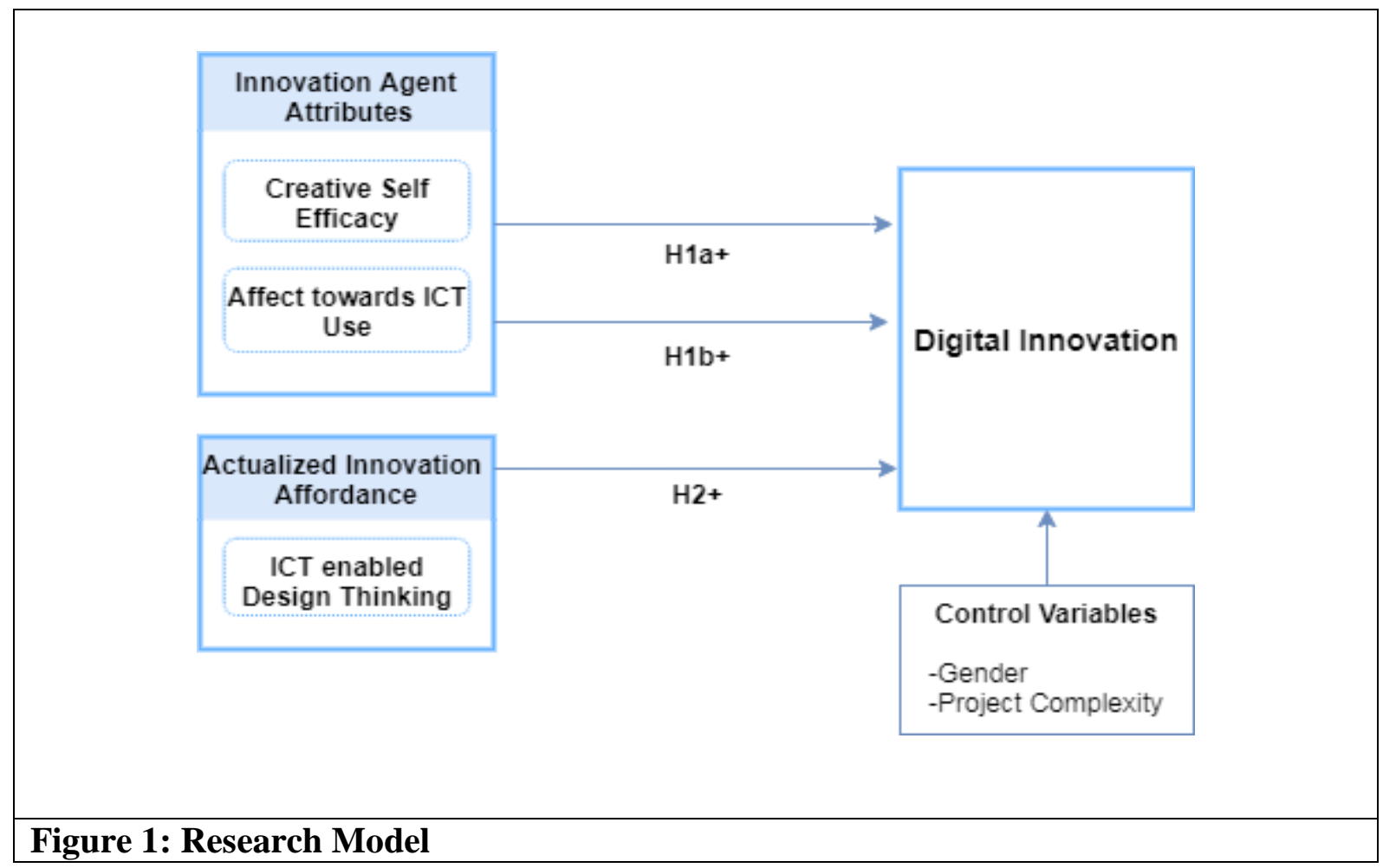

\section{Method}

\subsection{Research Setting}

Quasi-experimental method was adopted for our study. A two-wave temporally separated survey was used to collect data from respondents in a natural academic setting. The participants in the study were graduate students majoring either in engineering or management disciplines. All participants had enrolled in a joint collaborative academic program between a business school and an engineering school that share the same campus in France. The participants from both the schools, signed up for a weeklong graded collaborative academic program where the objective was to work on a collaborative digital social innovation project focused on alleviating societal problems. The participants were grouped into teams ensuring that there is a balanced mix of management and engineering students in all the teams. All the teams were introduced to the concept of design thinking as part of their creativity-training program on the first day of the program. The participants were encouraged to use design thinking innovation process for their projects. They had at their disposal the digital technology infrastructure including Internet access through Wi-Fi, engineering simulation tools, ICT communication tools, software and physical labs equipped with ICT and multimedia facilities that could be used for video production etc. Other proprietary or personal digital technologies were also allowed to be used for the purpose of the project. Thus, connected objects, personal PCs and laptops, mobile phones, smart phones, and social media technology tools were all used during the project. Two of the researchers had acted as a coach in a similar innovation training conducted earlier and were aware that students used digital tools at their disposal for such innovation projects. Participants worked as a team for a week in a flexible manner with minimum requirements on their physical presence. On the last day of the project, each team had to present their proof-ofconcept (POC) through a 3-minute video teaser and create a website describing their new venture detailing the elements of their digital social innovation. The teams were also asked to provide a 2-page synthesis of their innovation as a part of their grading process on the last day of the program. A total of 452 innovation agents participated in the week-long program. 


\subsection{Data Collection}

After obtaining the express permission from the program coordinators, the research data was collected from each of the team members in two temporally separated study waves in the form of surveys -first, at the start of the week-long program and second, at the end of the study project. The participants were informed about the nature of their voluntary participation in the study. 178 students responded to both the waves of the survey indicating a response rate of 39.4 percent, which is satisfactory for such an elaborate kind of a research design. Among the 178 respondents, the age of the majority of respondents ranged from 22 to 26 years. There were 105 male participants and 73 female participants who answered all the questions for the two surveys comprising this study.

Data on creative self-efficacy, affect towards ICT use and demographic variables were collected during the first wave of the survey. Data on ICT enabled design thinking creative process and ICT enabled digital innovation were collected during the second wave. Most of the constructs used in the study were adapted from validated construct scales from prior studies where psychometric properties have already been established. For example, we used the 3-item scale for 'affect towards ICT use' from Thompson et al., (1991), which has items such as "using ICTs makes work more interesting". We adapted 6-item scales for measuring creativity self-efficacy from Oldham \& Cummings (1996). Example items include; "I am confident about my ability to solve problems creatively"; "I feel that I am good at generating novel ideas". Project complexity construct was measured using scale from Baccardini (1996), where we asked questions on general complexity levels of the project, use of non-routine methodology and use of complex development processes in their projects. Digital innovation was measured using 3item scale adapted from (Tarafdar et al., 2010) - for example, "ICTs help me to try out innovative ideas"; "ICTs help me to come up with new ideas relating to my team tasks"; "ICTs help me to identify innovative ways of doing my team tasks". All constructs except, ICT enabled design thinking creative method have been modeled using reflective indicators. The newly conceptualized construct called ICT enabled design thinking creative method (ICT-DT) was developed as a formative construct during the study. We followed all the rigorous methodological procedures for the development and validation of the new 'ICT enabled design thinking' (ICT-DT) scale, the details of which are provided in Appendix B. Because the dependent variables may be influenced by factors other than those in the hypothesized model, we incorporated suitable control variables in our analysis to better understand the variance explained by the predictor variables. Specifically, "gender" and "project complexity" were used as controls because prior studies have found them to be significant factors. In addition, the study was conducted in a natural academic setting, hence the innovation reward-recognition objective climate is the same and can be assumed to be controlled for all the study participants.

\section{Data Analysis}

For the purpose of the data analysis, we used Partial Least Squares (PLS), a latent structural equation modeling technique, as implemented in Smart PLS 3.0, which utilizes a componentbased path modeling application (Ringle et al., 2005). PLS avoids the two major problems of inadmissible solutions and factor indeterminacy and is thus appropriate for analyzing complex models with latent variables (Fornell and Lacker, 1981; Wold, 1985). Many prior IS studies have found PLS to be a useful analytical tool (Setia et al., 2013; Srivastava and Chandra, 2018; Srivastava and Teo, 2010). We followed the recommended two-stage analytical procedure (Hair et al., 1998), where the first stage of data analysis evaluates the measurement properties of the constructs, and the second stage examines the structural relationships. Because our 
research model has both "reflective" and "formative" constructs, we need to undertake the measurement model assessment for both types of constructs.

\subsection{Evaluating Measurement Model for Reflective Constructs}

We tested three types of validity: content validity, convergent validity, and discriminant validity. Content validity assesses whether the chosen measures appropriately capture the full domain of the construct (Straub et al., 2004). We examined content validity by checking for consistency between the measurement items and the existing literature. This was done at the questionnaire design stage.

Convergent validity checks that the indicators for a construct are more correlated with one another than with the indicators of another construct (Petter et al., 2008). For this, we tested the measurement model with digital innovation as the dependent variable. Confirmatory factor analysis shows strong correlation between each of the items and their corresponding constructs (Table 1). This demonstrates convergent validity. We further tested convergent validity by examining the composite reliability (Craig, et al.) and average variance extracted (AVE: the ratio of the construct variance to the total variance among indicators) for the indicators (Hair $e t$ al., 1998). 0.70 is the suggested CR threshold for reliable measurement (Chin, 1998). As can be seen in Table 2, the CR values ranged from 0.85 to 0.90 . For the AVE, against the recommended threshold of 0.50 (Fornell \& Lacker, 1981), values ranged from 0.55 to 0.76. In addition, the high Cronbach alpha values, ranging from 0.74 to 0.84 , confirm the reliability of the scales for all the constructs.

We verified the discriminant validity of the various constructs by checking the square root of the average variance extracted, as recommended by (Fornell \& Lacker, 1981). The values of the square root of the AVE (shown on the diagonal in Table 3) are all greater than the corresponding inter-construct correlations (the off-diagonal entries below the square root of AVE in Table 3), exhibiting satisfactory discriminant validity. We also checked the crossloadings of the items on other constructs, which are quite low, indicating satisfactory discriminant validity (Table 1).

\begin{tabular}{|c|c|c|c|c|c|}
\hline & $\begin{array}{l}\text { Affect towards } \\
\text { technology }\end{array}$ & $\begin{array}{r}\text { Creative Self } \\
\text { efficacy }\end{array}$ & Gender & $\begin{array}{r}\text { ICT enabled } \\
\text { innovation }\end{array}$ & $\begin{array}{r}\text { Project } \\
\text { Complexity }\end{array}$ \\
\hline \multicolumn{6}{|c|}{$\begin{array}{l}\text { Affect towards } \\
\text { ICT use }\end{array}$} \\
\hline ATU1 & 0.87 & 0.15 & -0.01 & 0.31 & 0.20 \\
\hline ATU2 & 0.88 & 0.20 & -0.03 & 0.28 & 0.19 \\
\hline ATU3 & 0.79 & 0.16 & -0.08 & 0.27 & 0.11 \\
\hline \multicolumn{6}{|c|}{$\begin{array}{l}\text { Creative Self } \\
\text { Efficacy }\end{array}$} \\
\hline CSEFF1 & 0.23 & 0.71 & 0.22 & 0.18 & 0.05 \\
\hline CSEFF2 & 0.09 & 0.79 & 0.20 & 0.16 & 0.14 \\
\hline CSEFF3 & 0.05 & 0.69 & 0.02 & 0.17 & 0.08 \\
\hline CSEFF4 & 0.07 & 0.79 & 0.17 & 0.11 & 0.16 \\
\hline CSEFF5 & 0.20 & 0.75 & 0.05 & 0.25 & 0.14 \\
\hline CSEFF6 & 0.17 & 0.69 & 0.16 & 0.13 & -0.06 \\
\hline Gender & -0.04 & 0.17 & 1.00 & -0.05 & 0.01 \\
\hline \multicolumn{6}{|l|}{$\begin{array}{l}\text { Digital } \\
\text { innovation }\end{array}$} \\
\hline DINOV1 & 0.26 & 0.26 & -0.03 & 0.86 & 0.23 \\
\hline DINOV2 & 0.30 & 0.21 & -0.06 & 0.89 & 0.21 \\
\hline DINOV3 & 0.34 & 0.17 & -0.04 & 0.88 & 0.21 \\
\hline
\end{tabular}




\begin{tabular}{|l|r|r|r|r|r|}
\hline $\begin{array}{l}\text { Project } \\
\text { Complexity }\end{array}$ & & & & & \\
\hline PCOM1 & 0.06 & 0.13 & 0.08 & 0.13 & $\mathbf{0 . 7 6}$ \\
\hline PCOM2 & 0.19 & 0.10 & -0.02 & 0.21 & $\mathbf{0 . 7 8}$ \\
\hline PCOM3 & 0.13 & 0.08 & -0.02 & 0.23 & $\mathbf{0 . 8 8}$ \\
\hline Table 1: Factor Loadings and Cross-Loadings \\
\hline
\end{tabular}

\begin{tabular}{|l|r|r|r|r|}
\hline & $\begin{array}{r}\text { Cronbach's } \\
\text { Alpha }\end{array}$ & rho_A & $\begin{array}{r}\text { Composite } \\
\text { Reliability } \\
\text { (Craig, et al.) }\end{array}$ & $\begin{array}{r}\text { Average Variance } \\
\text { Extracted (AVE) }\end{array}$ \\
\hline Affect towards ICT use & 0.81 & 0.81 & 0.89 & 0.72 \\
\hline Creative Self efficacy & 0.84 & 0.86 & 0.88 & 0.55 \\
\hline Digital innovation & 0.85 & 0.85 & 0.91 & 0.77 \\
\hline Project Complexity & 0.74 & 0.78 & 0.85 & 0.65 \\
\hline \multicolumn{2}{|l|}{ Table 2: Measurement model for the assessment of reflective constructs } \\
\hline
\end{tabular}

\begin{tabular}{|l|r|r|r|r|r|}
\hline & $\begin{array}{r}\text { Affect } \\
\text { towards ICT } \\
\text { use }\end{array}$ & $\begin{array}{r}\text { Creative Self } \\
\text { efficacy }\end{array}$ & $\begin{array}{r}\text { ICT enabled } \\
\text { innovation }\end{array}$ & Gender & $\begin{array}{r}\text { Project } \\
\text { Complexity }\end{array}$ \\
\hline Affect towards ICT use & $\mathbf{0 . 8 5}$ & & & & \\
\hline Creative Self efficacy & 0.20 & $\mathbf{0 . 7 4}$ & & & \\
\hline Digital innovation & 0.34 & 0.24 & $\mathbf{0 . 8 8}$ & & \\
\hline Gender & -0.04 & 0.17 & -0.05 & $\mathbf{1 . 0 0}$ & \\
\hline Project Complexity & 0.17 & 0.12 & 0.25 & 0.01 & $\mathbf{0 . 8 1}$ \\
\hline Table 3: Construct correlations and the Fornell-Larcker criterion & & \\
\hline
\end{tabular}

\subsection{ICT enabled Design Thinking: Evaluation of Formative Measurement Construct}

We followed the recommended three-stage approach for evaluating the measurement properties of the sole formative construct - ICT enabled design thinking creative process (ICT-DT) (Hair et al., 2017). First, to establish the content validity of this construct, a thorough literature review was conducted with respect to different aspects and stages of the design thinking process. Based on the prior academic literature and industry practices, initial construct indicators were developed according to the five stages in the design thinking (DT) process namely-empathize, define, ideate, prototype, and test (Brown, 2010, Financial Brand, 2018). The measures for ICTDT were developed based on the extent to which different ICT tools were used for each of the five stages in the DT process. Empathize, is the first stage, where the individuals collect data about the real need or the problem that requires a creative solution. The second stage is to define the problem clearly with a view to solve it. In this stage, the individual needs to synthesize the gathered views to gain a refined understanding of the problem. The third phase is to ideate the meaning where individuals need to suggest or invent ideas for solving the problem. The fourth stage is to prototype tangible representations of the ideas. The last stage is to test the prototype with the potential users to check if the identified creative solutions are relevant to the needs of the intended users. For a good overview of the literature on design thinking please refer to Carlgren et al., (2016).

In this study, we examined the process of DT enabled by ICT. We posit that the described five phases of the human-centered design thinking approach are pertinent for any innovative process. Thus, the concept of DT is multifaceted and is formed together by all the phases and not a mere reflection of these five phases. Theoretically, these five components are enriched by ICT to comprise the full content of ICT-DT creative process. We first generated 12 items that 
represented the five stages and then refined the list of measures using a structured process with the help of 9 innovation experts who were either academics or heads of different innovation hubs (incubators). Table 4 provides more information on the background of the innovation experts who validated the newly constructed scale of ICT-DT. After finalizing the indicators for the ICT-DT scale, to make the measure parsimonious, we used one item to represent each of the five stages of design thinking process in the conceptualized formative construct for "ICT enabled design thinking" (ICT-DT) scale (Appendix B).

\begin{tabular}{|r|l|l|}
\hline S.No. & Title & Expertise \\
\hline 1. & $\begin{array}{l}\text { Associate Professor at Information Systems Department of } \\
\text { an European Business School }\end{array}$ & $\begin{array}{l}\text { Researcher in technology and } \\
\text { innovation }\end{array}$ \\
\hline 2. & $\begin{array}{l}\text { Full-Professor at Information Systems Department of an } \\
\text { European Business School }\end{array}$ & $\begin{array}{l}\text { Teacher, researcher and consultant } \\
\text { on design thinking and technology }\end{array}$ \\
\hline 3. & Director of Innovation Center from Columbia & Innovation Industry Expert \\
\hline 4. & An Incubator Co-Director from Mexico & Innovation Industry Expert \\
\hline 5. & An Incubator Director from Uruguay & Innovation Industry Expert \\
\hline 6. & Vice-President of Entrepreneurship Center from Peru & Innovation Industry Expert \\
\hline 7. & Director of Institutional Innovation Center in Paris, France & Innovation Industry Expert \\
\hline 8. & $\begin{array}{l}\text { Academic Director of International Relations from leading } \\
\text { university in America }\end{array}$ & $\begin{array}{l}\text { Academic coordinator responsible } \\
\text { for ensuring student collaboration on } \\
\text { innovative projects }\end{array}$ \\
\hline 9. & $\begin{array}{l}\text { Academic Coordinator of International Relations from } \\
\text { leading university in Argentina. }\end{array}$ & $\begin{array}{l}\text { Academic coordinator responsible } \\
\text { for ensuring student collaboration on } \\
\text { innovative projects }\end{array}$ \\
\hline Table 4: Profiles of experts consulted for validation of the newly formed scale of ICT-DT \\
\hline
\end{tabular}

Following the guidelines (Hair et al., 2017), we proceeded to evaluate the convergent validity of the formative construct. The convergent validity of the formative construct is measured by examining its correlation with an alternative measure of the construct, using reflective measures or a global single item measure (Hair et al., 2017). If the correlation between the formative construct and the reflective construct is above 0.70 then the construct is said to have convergent validity (Hair et al., 2017). Because there was no prior construct in the literature that represented DT or ICT-DT we had to use a new set of indictors that reflected each of the five stages of design thinking from the original pool of items generated using literature review. We then ran the redundancy test using the procedure prescribed by Hair et al., (2017). The correlation between the formative ICT-DT construct and the reflective ICT-DT construct was 0.97 , which is higher than the prescribed threshold of 0.70 . Thus, we conclude that the construct has a good convergent validity.

The next stage in establishing the measurement model for a formative construct is to examine the collinearity of the indicators comprising the formative construct. It is recommended that the VIF value for each indicator be lower than 5 . The VIF value for all the formative indicators ranged between 1.34 and 1.53 . We therefore concluded there is no significant multicollinearity between the indicators comprising the formative construct.

The third stage of evaluation for the formative construct involves assessing the significance and relevance of the formative construct. The significance of the outer weights is assessed to determine if all the chosen five indicators are relevant for explaining the proposed formative construct. After running the bootstrapping procedure, we found that the outer weights for the five items comprising ICT-DT were not significant. Therefore, we proceeded to check the outer loadings as per the decision process prescribed for such analysis (Hair et al., 2017) to assess their significance. All the outer loadings of the indicators for the ICT-DT construct were greater than or equal to 0.50 and were significant at $p<0.05$. Thus, we concluded that all items of the 
newly formed construct should be retained, and all are useful for explaining the focal formative construct. Moreover, to further tease out the discriminant validity of the ICT-DT construct and digital innovation construct in particular, we undertook a mediation method proposed by Wang et al., (2015) to gather evidence for the discriminant validity for the formative measurement. The results from this method supported discriminant validity of the ICT-DT construct (see Appendix C).

\subsection{Common Method Bias}

Common method bias can either inflate or deflate observed relationships between the constructs. Variance occurring due to the measurement method may cause systematic measurement error and further bias the true relationship among the theoretical constructs (Chandra, et al., 2012). In a critical review of common method bias in behavioral research (Podsakoff, et al., 2003) provide recommendations to alleviate common method bias by (1) using procedural remedies during study design, and (2) performing statistical checks. Similar to Srivastava et al., (2015b), we used a mix of procedural and statistical checks to ensure that common method bias did not confound our results. During the research design stage, the study was designed as a two-wave survey with a temporal separation of one week between the data collection on different sets of variables. By employing this procedure, we are were able to temporally detach some of the independent variables from the dependent variable. However, the time period of one week might be too short for avoiding a recall bias. Hence, we employed two further tests to ensure that common method bias did not confound our results.

First, to assess the severity of common method bias in the data we used Harman's one factor test (Podsakoff and Organ, 1986). Exploratory factor analysis revealed that the maximum variance explained by a single factor was $22.7 \%$, which was much lesser than the prescribed limit of $50 \%$. Hence, we can conclude that common method bias was not a significant problem with the data in our study (Podsakoff et al., 2003).

Second, for data analysis we are using partial least squares- structural equation modelling (PLSSEM) and our research model has both formative and reflective constructs. For such a situation, Kock (2015) has recommended the use of a "full collinearity variance inflation test" for checking if common method bias is confounding the results. Per Kock (2015) for identifying common method bias using PLS, the inner VIF values for both reflective and formative constructs can be utilized - "the occurrence of a VIF greater than 3.3 is proposed as an indication of pathological collinearity, and also as an indication that a model may be contaminated by common method bias. Therefore, if all VIFs resulting from a full collinearity test are equal to or lower than 3.3, the model can be considered free of common method bias" (Kock 2015, pp. 7). Our results presented in Appendix D allow us to conclude that there is no common method bias confounding our results as all the full collinearity variance inflation tests are lower than 3.3 .

Based on the design procedures and statistical checks described in this section, we can conclusively allay the possibility of common method bias confounding our data and results. In the next section, we take up the structural model assessment to check the hypothesized relationships.

\section{Results: Structural Model Assessment}

The results from the structural model are indicated in Table 5 and Figure 2. 


\begin{tabular}{|c|c|c|c|}
\hline \multirow[b]{2}{*}{ Control Variables } & \multicolumn{3}{|c|}{ Digital Innovation } \\
\hline & Model 1 & Model 2 & Model 3 \\
\hline & $\boldsymbol{\beta}$ & $\boldsymbol{\beta}$ & $\boldsymbol{\beta}$ \\
\hline Gender & -0.05 & -0.07 & -0.05 \\
\hline Project Complexity Perception & $0.25 * *$ & $0.18^{* *}$ & 0.04 \\
\hline \multicolumn{4}{|l|}{ Innovation Agent Variables } \\
\hline Creative Self Efficacy & & $0.18^{*}$ & $0.14 *$ \\
\hline Affect towards ICT use & & $0.27 * *$ & $0.17 *$ \\
\hline \multicolumn{4}{|l|}{ Innovation Affordance Variable } \\
\hline ICT enabled Design Thinking Creative Process & & & $0.51 * *$ \\
\hline $\mathrm{R}^{2}$ & 0.063 & 0.182 & 0.404 \\
\hline$\Delta \mathrm{R}^{2}$ & & $0.119 * *$ & $0.222 * *$ \\
\hline
\end{tabular}

The stepwise reporting of results using PLS is similar to other notable prior IS studies, such as Setia et al., (2013), Srivastava \& Chandra (2018), and Ann Sykes (2015). The results are presented in Table 5 as a stepwise hierarchical structural model, where in the step 1 only control variables are introduced, in step 2 we introduce innovation agent attributes (creative selfefficacy and affect towards ICT use) in addition to the control variables and in step 3, we add the actualized innovation affordance (ICT-DT). We observe that among the control variables entered in model 1 , gender is not significant $(\beta=-0.05, p>0.05)$ but the perception of project complexity is significantly related to digital innovation $(\beta=-0.25, \mathrm{p}<0.01)$. In the model 2 , we note that innovation agent's 'creative self-efficacy' is significantly related to digital innovation $(\beta=0.18, p<0.05)$, supporting H1a. Similarly, 'affect towards ICT use' has a significant relationship with digital innovation $(\beta=0.27, p<0.01)$, thereby providing support to H1b. Model 3 provides us insights on actualized innovation affordance where ICT enabled design thinking (ICT-DT) is found be significantly related to digital innovation $(\beta=0.57, \mathrm{p}<0.01)$, supporting $\mathrm{H} 2$.

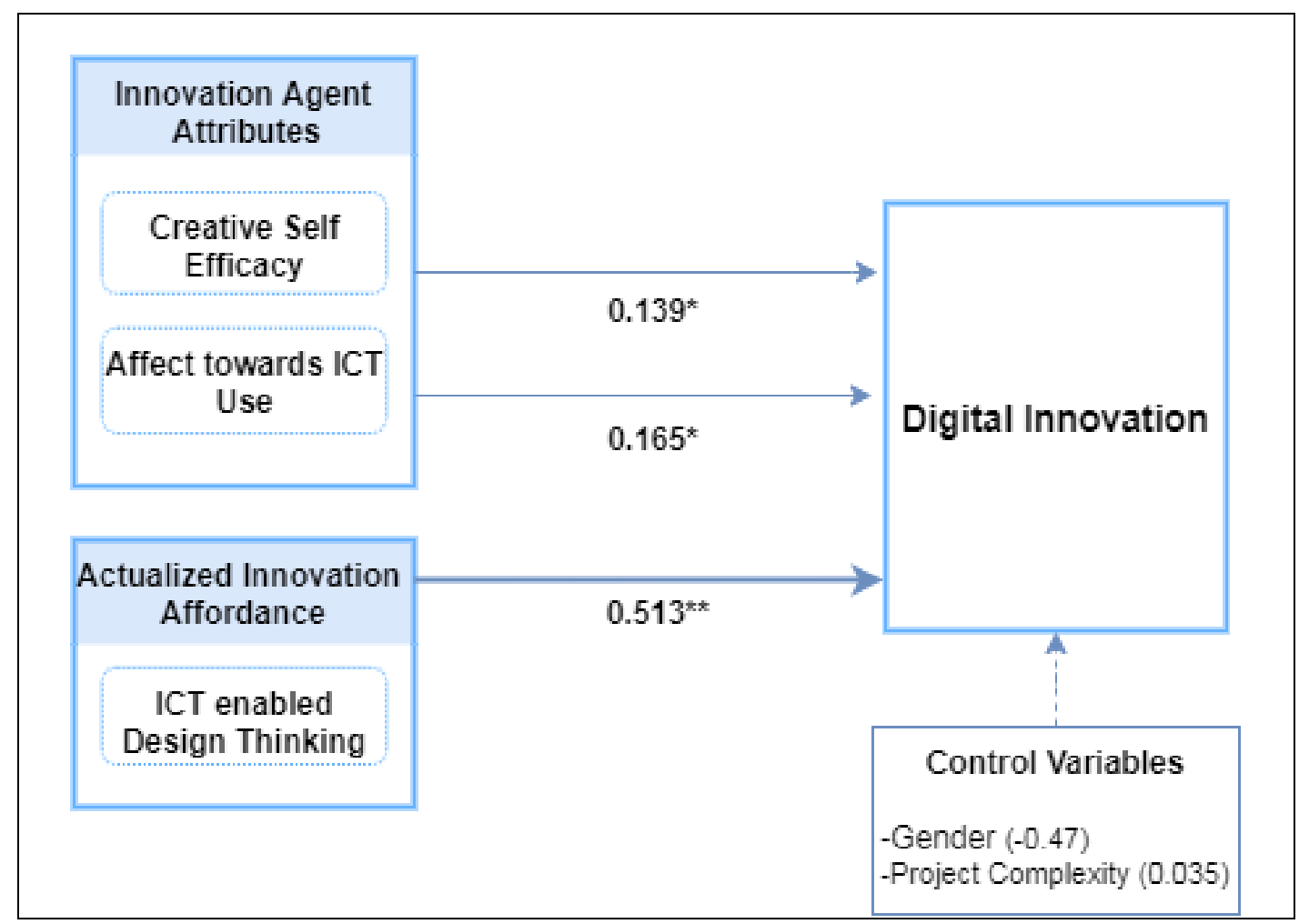


$\mathrm{N}=178$; ** indicates $\mathrm{p}$ value $<0.01 ; *$ indicates a $\mathrm{p}$ value $<0.05$; Other paths are non-significant

Figure 2: Structural model - Relationships of controls variables, innovation agent attributes and actualized innovation affordance with digital innovation

For the evaluation of the predictive relevance of the structural model, the Stone and Geisser $\mathrm{Q}^{2}$ test was performed using the blindfolding procedure (Geisser, 1974, Stone, 1974). The blindfolding test, which was conducted with omission distance equals to 7 (the recommended number), revealed that all $\mathrm{Q}^{2}$ values of endogenous variable was greater than zero (digital innovation) -0.33 for model 1 and 0.12 for model 2 and 0.27 for model 3. Positive $Q^{2}$ values provide evidence of the predictive relevance from the research sample size.

The $\mathrm{R}^{2}$ or variance explained from each model further elaborates that the control variables only explained $6.3 \%$ of the variance in digital innovation (Model 1). However, 'innovation agent attributes' together with control variables explains $18.2 \%$ of the variance in digital innovation (Model 2). Whereas 'actualized innovation affordance' (ICT-DT) together with control variables and innovation agent attributes explain $40.4 \%$ of variance in digital innovation (Model $3)$. Further, the change in variance $\left(\Delta \mathrm{R}^{2}\right)$ from Model 2 to Model 3 is significant to the extent of $22.2 \%$ in contrast to only $11.9 \%$ change from Model 1 to Model 2 . This clearly highlights the relatively greater importance of 'actualized innovation affordance' (in the form of ICT enabled design thinking) in comparison to 'innovation agent attributes' (creative self-efficacy and affect towards ICT use).

\section{Discussion}

In this section, we first deliberate on the obtained results, followed by a discussion on the theoretical and practical implications stemming from our study. Concurrently, we also point out to the study's limitations and identify several interesting avenues for future research that can complement and expand our work.

Based on the results presented in the prior section, we observe that all the hypotheses in this study are generally supported. The results for $\mathrm{H} 1 \mathrm{a}$ and $\mathrm{H} 1 \mathrm{~b}$ show that "innovation agent attributes" of 'creative-self efficacy' and 'affect towards ICT use' together explain about 18 percent of the variance in digital innovation. Hence, it is important for digital innovation research to bring together context specific variables from the two disciplines of creativity and IS research. Although 'creative self-efficacy' is a well-established concept in the field of creativity research (Amabile, 1996), it has not been previously examined in the context of digital innovation. In a similar vein, 'affect towards ICT use' has been found to be a useful variable for explaining different IS contexts (Thompson et al., 1991), it had not yet been used to understand digital innovation. Clearly, digital innovation needs to be viewed from an interdisciplinary perspective to have a holistic understanding on the subject. In addition, results show that both domain generic and domain specific intrapersonal innovation agent attributes influence digital innovation, which we believe is a novel addition to the current understanding on digital innovation (Amabile, 1996).

The results for $\mathrm{H} 2$ show that actualized innovation affordance orchestrated through ICT-DT is positively associated with digital innovation, which establishes the salient role of ICT-DT for facilitating digital innovations at the individual level of analysis (Pozzi et al., 2014; Burton and Volkoff, 2018). Our study answers to calls for integrating creativity and digital innovation 
literature (Fichman et al., 2014) and also offers a contextual explanatory theory of 'effective use of existing IS' for facilitating digital innovation (Burton and Volkoff, 2018; Unsworth, 2001). At lower levels of abstraction, our study provides validation for the efficacy of ICT-DT approach for creative innovation process, thereby contributing to the growing ecological perspective on understanding the micro-foundations to creativity and digital innovation (Isaksen et al., 1993).

Actualized innovation affordance explains about 22 percent of variance in 'digital innovation' at the individual level. The study at a more generic level allows us to empirically discern the role of ICT-enabled design thinking creativity process in digital innovation context which has been missing from literature thus far (Burton and Volkoff, 2018). Developing creativity support tools specifically for design thinking process in a holistic manner is a fruitful area for future research. Further, we show that, similar to other innovative processes, both the "innovation agent attributes and the "actualized innovation affordances" enacted by the innovation agent are important for facilitating digital innovation. In fact, their additive influence explains 40 percent of variance in 'digital innovation'. However, we observe that the role of actualized innovation affordance is more salient for facilitating digital innovation. Our research validates the need for facilitating the imbrication of human and material agencies to support the goal of innovation agent (Lubart et al., 2005; Glăveanu et al., 2019; Ciriello et al., 2017). Our results also align well with recent research that examines how digital innovation and technology use are linked at the organizational level. Generic technologies can offer actualized affordance for facilitating digital innovation provided collective human agency attributes match well with the task specific goals (Chatterjee et al., 2020).

The control variable of project complexity has positive influence on digital innovation. It may be interesting to consider project complexity as a novel boundary condition to "effective use of IS' in the context of digital innovation. Lenfle and Loch (2010) have highlighted that project complexity can lead to emergent learnings and 'learning by doing' as a process outcome. This resonates with the use of design thinking approach for digital innovation enactment, as iterations and learning are integral to such an innovation management approach. Therefore, one may envision that project complexity may moderate the relationship between actualized innovation affordance and digital innovation. We did not theorize for such a relationship; however, future research can examine the role of project complexity in facilitating digital innovation outcomes through a structured innovation method. Such an enquiry can help further contextualize the 'effective use of IS theory' to the digital innovation milieu (Burton and Volkoff, 2018).

Our study has been conducted using a student sample, which may limit its generalizability to the real-world scenario. Future research can examine the findings of the study in the context of organizations and real-world professionals. The competence and motivation levels of an innovation agent may differ across student and professional samples. Our study did not check for any counter-factual hypotheses, future research can add such notions to their studies to uncover any potential limitations, such as team-level biases or other contextual factors in nondigital innovation settings that can limit the applicability of the proposed model. Although in our study, we have examined the role of affect towards ICT use as a facilitator for digital innovation, it is possible that negative affect towards use can have a different influence. Negative affect towards ICT might impel the innovation agents to not use (or use less) ICT for innovation. It could be interesting to theorize and examine how negative affect towards ICT use influences the enactment and the outcome of digital innovation. Our study investigates individuals embedded in teams; future empirical studies can investigate this research model 
purely at team levels after validating the new scale on ICT-DT, similar to recent studies looking at DT's impact on team creativity outcomes (Nagaraj et al., 2020). Future studies can also theorize the influence of digital affordance factors on process outcomes and team effectiveness outcomes separately to offer a nuanced evaluation. For example, the notions of team climate and team psychological empowerment perceptions may interact with team level innovation affordance to influence team process and effectiveness outcomes. A multilevel study can also be undertaken to examine if any of the team level factors influence the individual perceptions of innovation affordance and consequent individual-level digital innovation outcomes. Further, a qualitative study on the subject can help tease out the roles of different technologies in increasing or decreasing innovation affordance. In addition to providing several directions for future research, our study has several theoretical and practical implications, which we discuss in the following section.

\subsection{Theoretical Implications}

Our research makes three key theoretical contributions. First, we contribute to affordance and effective use literatures at the broad level. We demonstrate the value of the 'effective IS use' perspective in conceptualizing the task of achieving digital innovation as an outcome of effectively leveraging the right user competencies and using a structured method for orchestrating the available technological systems in an organization (Burton-Jones and Grange 2013; Burton-Jones and Volkoff 2017). Our results clearly show the salience of innovation agent attributes and an actualized innovation affordance through the effective use of available technologies for facilitating digital innovation. Specifically, we contextualize the undertheorized aspect of socio-materiality of digital innovation orchestration at innovation agent level in a nontraditional natural field setting using effective use lens (Yoo et al., 2012; Nambisan et al., 2017). We demonstrate that both - domain specific innovation agent attributes and domain specific actualized innovation affordances, act as a micro-foundation (resources) for individual level digital innovation. This finding extends other recent research that holistically tries to understand how generic organizational technology use is linked to digital innovation through the affordance lens (Chatterjee et al., 2020)

Second, in addition to the broad level contributions described above, we offer nuanced contributions to technology affordance and digital innovation literature. We theorize and show the extent to which specific resource mobilization potential embedded in innovation agent attributes and actualized innovation affordance can facilitate digital innovation. At the micro level, our study argues for the co-alignment of human attributes and technology affordance perceptions for actualization of technology creativity affordance in the context of digital innovation. This extends recent study that look at the co-alignment of collective human agency (values) and technology affordance perceptions for orchestrating digital innovation at the organizational level (Chatterjee et al., 2020). By teasing out "creativity self-efficacy" as domain specific human agent attribute and "affect towards ICT use" as technology specific human agent attribute, we demarcate the two unique type of individual level resources for digital innovation at the micro level. The study, thus extends the emerging literature around digital innovation by providing contextual and nuanced understanding that incorporates domain specific innovation agent attributes and actualized innovation affordances perceived by agents as they enact structured digital innovation practices (Ciriello et al., 2017). The findings from our study can help organizations appreciate the importance of specific innovation agent attributes to better staff innovation projects. 
Third, we demonstrate the significant role of using ICT for implementing a structured creative approach such as ICT-DT for facilitating innovation. The results highlight the salience of design thinking creative process for digital innovation and the need to look for other similar structured approaches to exploit the digital technologies for innovation in terms of an actualized innovation affordance. We believe that the current study is one of the first to theorize the role of actualized innovation affordance in facilitating digital innovations at the individual level. Specifically, the study demonstrates the greater importance of innovation affordance - in the form of 'ICT enabled design thinking creative method' (ICT-DT), in comparison to innovation agent attributes, for facilitating digital innovation. Thus, we contribute to both - digital innovation literature that has called for more research in "exploitation" of digital technology for digital innovation, and the interactional ecological perspective on creativity and digital innovation by conceptualizing innovation affordance as an actual mangling of practices between technology and human creative process (Barrett et al., 2012; Livingstone et al., 1997; Nambisan et al., 2017). Moreover, our work enriches the rather sparse literature that links individual-level creativity engagement with digital innovation (Fichman et al., 2014). The study also integrates the creativity literature with the digital innovation literature by examining the influence of expected creativity on digital innovation (Unsworth, 2001).

\subsection{Methodological Contribution}

Our research conceptualizes and empirically establishes the importance of having a structured innovation approach, specifically, ICT-DT for digital innovation. Our study contributes to the literature by operationalizing ICT-DT measured as a five-item formative construct. The conceptualized construct can be used by future research to examine the salience of ICT-DT in different contexts. The validated scale can also contribute to the stream of literature that investigates the performative aspects of design thinking (see Carlgren et al., 2016).

\subsection{Practical Implications}

First, the results from our study encourages innovation practitioners to provide digital infrastructure to innovation agents for actively leveraging its use for innovation. The study demonstrates that the imbrication of human and material technologies can contribute to an affordance perception and enactment for creativity related tasks.

Second, our study informs human resource practitioners that care should be taken while relying only on multivariate and cognitive determinants of creativity for the selection of employees for innovative digital projects. The results from our study demonstrate that an ecological perspective is more effective in facilitating digital innovation. Hence, the managerial focus should be on providing a supportive method-based environment that offers a framework to the workers for enabling a creative output. ICT-DT, conceptualized and proposed in this study, can be one of the structured approaches that can be effective in facilitating digital innovation.

Third, human resource practitioners should take into consideration the role of domain specific and task specific innovation agent attributes such as "creativity self-efficacy beliefs" and "technology specific positive affect" for facilitating digital innovations, rather than relying solely on general traits and capabilities. In this context, it may be prudent to evaluate aspects of individual's cognitive biases such as the technological frames and the influence of these biases 
on innovation affordance (Shirish, 2020). However, more research on this aspect is warranted and can be a potential extension of our work.

Fourth, the results from this study are practically useful in understanding the extent to which DT creative process can facilitate social and digital innovation amongst young adults. The pervasive use of technologies by digital natives provides evidence that even without the structured use of a specific enterprise level creative support system there could be an emergence of innovation affordance (e.g., Shirish et al., 2016; Chandra et al., 2019). Therefore, designthinking approach can be a useful creative process that can be applied to all types of innovation contexts including those that are distributed or rely on open innovation, such as - social media, mobile applications, analytics, cloud computing and internet of things (Chan et al., 2019). However, it remains to be seen, if the relevance of the ICT-DT as an actualized innovation affordance will be applicable to all areas of innovation beyond the context of 'digital' innovation because many new product development teams are focused on creative output but not necessarily digital innovation (Nagaraj et al. 2020). It is also possible for future research to examine how ICTs may constrain a specific innovation process (Ciriello et al., 2019).

Another related implication for practitioners and future researchers is to develop a configurational approach to the digital innovation process (see Isaksen et al., 1993). A configurational perspective to digital innovation will allow experimentation on different user profiles in conjunction with appropriate environmental factors for a specific type of innovation problem. Such a nuanced understanding is currently lacking in literature and can be a useful avenue for future research. Configuration can comprise a combination of factors such as innovation agent capabilities, suitable technological infrastructure, a supportive environment, and a congruent problem-solving situation. Research on the influence of specific typologies of such configurations for facilitating digital innovation will help design proactive innovation strategies. In the present study, the problem that required a creative solution was open ended and unstructured. This is different from most actual situations in organizations that may warrant a responsive creativity to a specific problem, which is based on close-ended creative solutions (Srivastava et al., 2013; Unsworth, 2001). Future research can explore responsive creativity and the role of ICT-DT in facilitating planned innovation.

\section{Conclusion}

With the growth in the availability of digital resources, it is necessary for organizations to understand and implement the modalities for leveraging the available ICTs for their innovation endeavors. Grounding our work in the theory of effective IS use and taking a technology affordance perspective, we posit that for facilitating digital innovations organizations need to focus on two key elements, namely 'innovation agent attributes' and an 'actualized innovation affordance'. We conceptualize the domain generic and domain specific innovation agent attributes of 'creative self-efficacy' and 'affect towards ICT use' and an actualized innovation affordance through 'ICT enabled design-thinking approach' (ICT-DT). We contend that ICTDT offers one possible structured approach to effectively use digital resources within an organization for innovation. By integrating creativity and digital innovation literature, our theorization delineates the mechanisms through which the goal-directed 'problem-solvingpotential' of the innovation agent and the 'problem-solution-matching' through actualized innovation affordance, can facilitate digital innovation (Nambisan et al., 2017). Findings highlight the significant role of innovation agent attributes and innovation affordance as microfoundations for digital innovation. In particular, both the hypothesized innovation agent attributes of 'creative self-efficacy' and 'affect towards ICT use' are significant facilitators of 
digital innovation. In addition, the actualized innovation affordance operationalized through ICT-DT is a significant determinant of digital innovation. However, results demonstrate the stronger association of ICT-DT with digital innovation, highlighting the need for organizations to integrate the use of technologies for enabling structured creativity approaches (such as DT) for facilitating innovative outcomes. Based on our study we also suggest several avenues for future research that can serve to enrich the field of digital innovation and creativity.

\section{References}

Alves, R. and N. J. Nunes (2013). "Towards A Taxonomy of Service Design Methods and Tools". In International Conference on Exploring Services Science, Springer, Berlin, Heidelberg. p. 215-229

Amabile T.M. (1983), "The Social Psychology of Creativity: A Componential Conceptualization", Journal of Personality and Social Psychology, vol. 45, n², p. 357-376.

Amabile T.M. (1996), "Creativity in Context" in Westview press, Boulder, Colorado,

Amabile T.M.Pratt M.G. (2016), "The Dynamic Componential Model of Creativity and Innovation in Organizations: Making Progress, Making Meaning", Research in Organizational Behavior, vol. 36, p. 157-183.

Andriani P.Cattani G. (2016), "Exaptation as Source of Creativity, Innovation, and Diversity: Introduction to the Special Section", Industrial and Corporate Change, vol. 25, n 1 , p. 115 131.

Ann Sykes, T. (2015), "Support Structures and their Impacts on Employee Outcomes: A Longitudinal Field Study of an Enterprise System Implementation", MIS Quarterly, vol. 39, $\mathrm{n}^{\circ} 2$, pp. 473-495.

Ashkanasy N.M.Dorris A.D. (2017), "Emotions in the Workplace", Annual Review of Organizational Psychology and Organizational Behavior, vol. 4, n 67-90,

Austin R.D., Devin L.Sullivan E.E. (2012), "Accidental Innovation: Supporting Valuable Unpredictability in the Creative Process", Organization Science, vol. 23, n 5, p. 505-1522.

Baccardini D. (1996), "The Concept of Project Complexity: A Review", International Journal of Project Management, vol. 14, $\mathrm{n}^{\circ} 4$, p. 201-204.

Bandura A. (1977), "Self-Efficacy: Toward a Unifying Theory of Behavioral Change", Psychological Review, vol. 84, n², p. 191-215.

Bandura A. (1982), "Self-Efficacy Mechanism in Human Agency", American Psychologist, vol. 37, n², p. 122-147.

Bandura A. (2001), "Social Cognitive Theory: An Agentic Perspective", Annual Review of Psychology, vol. 52, $\mathrm{n}^{\circ}$ 1, p. 1-26.

Barrett M., Oborn E., Orlikowski W.J. Yates J. (2012), "Reconfiguring Boundary Relations: Robotic Innovations in Pharmacy Work", Organization Science, vol. 23, n5, p. 1448-1466.

Bernhard, E., Recker, J.C. and Burton-Jones, A. (2013), "Understanding the actualization of affordances: A study in the process modeling context" in Proceedings of the 34th International Conference on Information Systems (ICIS 2013), M. Chau and R. Baskerville (Eds), Association for Information Systems (AIS), p. 1-11.

Bledow, R., Schmitt, A., Frese, M. and Kühnel, J. (2011), "The Affective Shift Model of Work Engagement", Journal of Applied Psychology, vol. 96, n6, p. 1246.

Brown T. (2010), "Change by Design", Harper Collins.

Brown T.Martin R. (2015), "Design for Action: How to Use Design Thinking to Make Great Things Happen", Harvard Business Review, p. 58-64.

Boukef, N and Charki, M H. (2019). "The Millefeuille theory revisited. New theoretical lenses to understand the Millefeuille effect", Systèmes d'Information et Management, vol. 24, $\mathrm{n}^{\circ}$ 2, p. 47-83. 
Burkhardt J.M.Lubart T. (2010), "Creativity in the Age of Emerging Technology: Some Issues and Perspectives", Creativity and Innovation Management, vol. 19, n², p. 160-166.

Burton-Jones, A. and Grange, C. (2013), "From Use to Effective Use: A Representation Theory Perspective", Information Systems Research, vol. 24, n³, p. 632-658.

Burton-Jones, A. and Straub Jr, D.W. (2006), "Reconceptualizing System Usage: An Approach and Empirical Test", Information Systems Research, vol. 17, n³, p. 228-246.

Burton-Jones, A. and Volkoff, O. (2017), "How Can We Develop Contextualized Theories of Effective Use? A Demonstration In the Context of Community-Care Electronic Health Records", Information Systems Research, vol. 28, n³, p. 468-489.

Carlgren L., Rauth I. Elmquist M. (2016), "Framing Design Thinking: The Concept in Idea and Enactment", Creativity and Innovation Management, vol. 25, ${ }^{\circ} 1$, p. 38-57.

Chan Y., Ahuja S., Boroom and F.Sadreddin A. (2019), "Technology Affordances in Digital Innovation Research: Quo Vadis?", In 2019 AMCIS Proceedings, Cancun, Mexico.

Chandra S., Shirish A.Srivastava S.C. (2019), "Does Technostress Inhibit Employee Innovation? Examining the Linear and Curvilinear Influence of Technostress Creators", Communications of the Association for Information Systems, vol. 44, n 1, p. 299-331.

Chandra S., Srivastava S.C. Theng Y.L. (2012), "Cognitive Absorption and Trust for Workplace Collaboration in Virtual Worlds: An Information Processing Decision Making Perspective." Journal of the Association for Information Systems, vol. 13, n ${ }^{\circ} 10$, p. 797-835.

Chasanidou, D., Gasparini, A.A. and Lee, E. (2015), "Design Thinking Methods and Tools for Innovation" in International Conference of Design, User Experience, and Usability, Springer, p. 12-23.

Chatterjee, S., Moody, G., Lowry, P.B., Chakraborty, S. and Hardin, A. (2020), "Information Technology and Organizational Innovation: Harmonious Information Technology Affordance And Courage-Based Actualization", The Journal of Strategic Information Systems, vol. 29, n 1 , p. 101596.

Chin W.W. (1998), "The Partial Least Squares Approach for Structural Equation Modelling" in Modern Methods for Business Research, Marcoulides (Ed), Lawrence Erlbaum, Mahwah, New Jersey.

Choi J.N. (2004), "Individual and Contextual Predictors of Creative Performance: The Mediating Role of Psychological Processes", Creativity Research Journal, vol. 16, p. 187199.

Ciriello R.F. Richter A. (2015), "Idea Hubs as Nexus of Collective Creativity in Digital Innovation" in Thirty Sixth International Conference on Information Systems (ICIS), Fort Worth, USA,

Ciriello R.F., Richter A. Schwabe G. (2017),"From Process to Practice: Towards a PracticeBased Model of Digital Innovation" in Thirty Eighth International Conference on Information Systems (ICIS), South Korea.

Ciriello R.F., Richter A. Schwabe G. (2019), "The Paradoxical Effects of Digital Artefacts on Innovation Practices", European Journal of Information Systems, vol. 28, n², p. 149-172.

Cooper R., Junginger S. Lockwood T. (2009), "Design Thinking and Design Management: A Research and Practice Perspective", Design Management Review, vol. 20, n², p. 46-55.

Costa C.G.d., Zhou Q. Ferreira A.I. (2017), "The Impact of Anger on Creative Process Engagement: The Role of Social Contexts", Journal of Organizational Behavior, p. 1-12.

Couger J.D., Higgins L.F. McIntyre S.C. (1993), "(Un) Structured Creativity in Information Systems Organizations", MIS Quarterly, p. 375-397.

Craig, K., Thatcher, J.B. and Grover, V. (2019), "The IT Identity Threat: A Conceptual Definition and Operational Measure", Journal of Management Information Systems, vol. 36, $\mathrm{n}^{\circ} 1$, p. 259-288. 
da Silva, I.F. (2020), "Describing the Design Thinking and Extreme Programming Activities During A Technology Innovation Academic Workshop", Innovation \& Management Review, Vol. 17, n³, p. 264-284.

DDM, The Design Management Institute (2020), "DMI Value Index 2015" , https://www.dmi.org/page/2015DVIandOTW, last accessed on 20 March 2021.

Diliello T.C., Houghton J.D. Dawley D. (2011), "Narrowing the Creativity Gap: The Moderating Effects of Perceived Support for Creativity", The Journal of Psychology, vol. $145, n^{\circ} 3$, p. 151-172.

Drazin R., Glynn M.A. Kazanjian R.K. (1999), "Multilevel Theorizing About Creativity in Organizations: A Sensemaking Perspective", Academy of Management Review, vol. 24, n², p. 286-307.

Dumas A. Mintzberg H. (1989), "Managing Design Designing Management", Design Management Journal (Former Series), vol. 1, n 1, p. 37-43.

Dumas A. Mintzberg H. (1991), "Managing the Form, Function, and Fit of Design", Design Management Journal (Former Series), vol. 2, n³, p. 26-31.

Elsbach K.D. Stigliani I. (2018), "Design Thinking and Organizational Culture: A Review and Framework for Future Research", Journal of Management, vol. 44, n6, p. 2274-2306

Farr, J. L. and C. M. Ford (1990). "Individual innovation". In Innovation and Creativity at Work: Psychological and Organisational Strategies,. M. A. West and J. L. Farr. Chichester, Wiley.

Fichman, R.G. (2004), "Going Beyond the Dominant Paradigm for Information Technology Innovation Research: Emerging Concepts and Methods", Journal of the Association for Information Systems, vol. 5, n 8, p. 329-253

Fichman R.G., Dos Santos B.L., Zheng Eric Z. (2014), "Digital Innovation as a Fundamental and Powerful Concept in the Information Systems Curriculum", MIS Quarterly, vol. 38, n², p. 329-253.

Financial Brand (2018),"Design Thinking: The Hottest New Trend in Banking", https://thefinancialbrand.com/70152/design-thinking-banking-financial-innovation/, last accessed on 06 June 2018.

Ford C.M. (1996), "A Theory of Individual Creative Action in Multiple Social Domains", Academy of Management Review, vol. 21, n¹112-1142,

Fornell C. Lacker D. (1981), "Evaluating Structural Equation Models with Unobservable Variables and Measurement Error", Journal of Marketing Research, vol. 18, n¹, p. 39-50.

Forrester (2019),"Design Thinking Can Deliver an Roi of $85 \%$ or Greater", https://go.forrester.com/blogs/design-thinking-can-deliver-an-roi-of-85-or-greater/, last accessed on 19 April 2020.

Frese, M., Teng, E. and Wijnen, C.J. (1999), "Helping to Improve Suggestion Systems: Predictors of Making Suggestions In Companies", Journal of Organizational Behavior, vol. 20, n 7 , p. 1139-1155.

Gabriel A., Monticolo D., Camargo M. Bourgault M. (2016), "Creativity Support Systems: A Systematic Mapping Study", Thinking Skills and Creativity, vol. 21, p. 109-122.

Gartner (2019),"Enterprise Architects Combine Design Thinking, Lean Startup and Agile to Drive Digital Innovation", https://www.gartner.com/en/documents/3941917/enterprisearchitects-combine-design-thinking-lean-start , last accessed on 14 January 2020.

Geisser S. (1974), "A Predictive Approach to the Random Effect Model", Biometrika, vol. 61, $n^{\circ} 1$, p. 101-107.

George J.M. Zhou J. (2002), "Understanding When Bad Moods Foster Creativity and Good Ones Don't: The Role of Context and Clarity of Feelings", Journal of Applied Psychology, vol. 87, n 4, p. 687-697. 
George J.M. Zhou J. (2007), "Dual Tuning in a Supportive Context: Joint Contributions of Positive Mood, Negative Mood, and Supervisory Behaviors to Employee Creativity", Academy of Management Journal, vol. 50, n³, p. 605-622.

Glăveanu V.P., Ness I.J., Wasson B. Lubart T. (2019), "Sociocultural Perspectives on Creativity, Learning, and Technology" in Creativity under Duress in Education?, Springer, Cham, p. 63-82.

Glen R., Suciu C. Baughn C. (2014), "The Need for Design Thinking in Business Schools", Academy of Management Learning \& Education, vol. 13, nº 4, p. 653-667.

Godé, C., Brion, S. and Bohas, A. (2020), "The Affordance-Actualization Process in a predictive Policing Context: Insights from the French Military Police" In 28th European Conference on Information Systems (ECIS), An Online AIS Conference.

Gong Y., Huang J.C. Farh J.L. (2009), "Employee Learning Orientation, Transformational Leadership, and Employee Creativity: The Mediating Role of Employee Creative SelfEfficacy. ", Academy of management Journal, vol. 52, n 4, p. 765-778.

Gruber M., De Leon N., George G. Thompson P. (2015), "Managing by Design", Academy of Management Journal, vol. 58, ${ }^{\circ} 1$, p. 1-7.

Hair J.F., Black W.C., Babin B.J., Anderson R.E. Tatham R.L. (1998), "Multivariate Data Analysis " in Prentice hall., Upper Saddle River, NJ, p. 207-219.

Hair J.F., Sarstedt M., Ringle C.M. Gudergan S.P. (2017), "Advanced Issues in Partial Least Squares Structural Equation Modeling", Sage Publications, Thousand Oaks, CA.

Hammond, M.M., Neff, N.L., Farr, J.L., Schwall, A.R. and Zhao, X. (2011), "Predictors Of Individual-Level Innovation at Work: A Meta-Analysis", Psychology of Aesthetics, Creativity, and the Arts, vol. 5, ${ }^{\circ} 1$, p. 90.

Isaksen S.G., Puccio G.J. Treffinge D.J. (1993), "An Ecological Approach to Creativity Research: Profiling for Creative Problem Solving", The Journal of Creative Behavior, vol. 27, n³, p. 149-170.

Jeyaraj, A., Rottman, J.W. and Lacity, M.C. (2006), "A review of the predictors, linkages, and biases in IT innovation adoption research", Journal of information technology, vol. 21, ${ }^{\circ} 1$, p. 1-23.

Johansson-Sköldberg U., Woodilla J. Çetinkaya M. (2013), "Design Thinking: Past, Present and Possible Futures", Creativity and Innovation Management, vol. 22, n², p. 121-146.

Kiviniemi M.T. Duangdao K.M. (2009), "Affective Associations Mediate the Influence of Cost-Benefit Beliefs on Fruit and Vegetable Consumption", Appetite, vol. 53, n³, p. 771775 .

Kock N. (2015), "Common Method Bias in Pls-Sem: A Full Collinearity Assessment Approach", International Journal of e-Collaboration, vol. 11, n4, p. 1-10.

Koenig-Lewis N. Palmer A. (2014), "The Effects of Anticipatory Emotions on Service Satisfaction and Behavioral Intention", Journal of Services Marketing, vol. 28, nº, p. 437 451.

Kohli R. Melville N.P. (2019), "Digital Innovation: A Review and Synthesis", Information Systems Journal, vol. 29, n¹, p. 200-223.

Kubicek B., Hoelzl E. Korunka C. (2013), "Emotion Regulation Requirements and Affective Forecasts Regarding Expected Organizational Changes", Horizons of Psychology, vol. 22, p. 1-13.

Leonardi, P.M. (2011), "When Flexible Routines Meet Flexible Technologies: Affordance, Constraint, and The Imbrication of Human And Material Agencies", MIS Quarterly, vol. 35, $\mathrm{n}^{\circ} 1$, p. 147-167.

Lee, J. and Berente, N. (2012), "Digital Innovation and the Division of Innovative Labor: Digital Controls In The Automotive Industry", Organization Science, vol. 23, n5, p. 14281447. 
Lee, L.Y. And Qomariyah, A. (2015), "Exploring Expatriate Adjustment from Expatriate's Intelligence And Family Adaptability: A Meta-Analytic Approach", International Journal Of Social Sciences \& Education, vol. 5, N², P. 374.

Lenfle, S. (2008), "Exploration and project management", International Journal of Project Management, vol. 26, $\mathrm{n}^{\circ}$ 5, p. 469-478.

Lenfle, S. and Loch, C. (2010), "Lost roots: How Project Management Came to Emphasize Control over Flexibility and Novelty", California Management Review, vol. 53, n 1, p. $32-$ 55.

Liedtka J. (2017), "Evaluating the impact of design thinking in action" in Academy of Management Proceedings, Atlanta, Georgia.

Lim H.S. Choi J.N. (2009), "Testing an Alternative Relationship between Individual and Contextual Predictors of Creative Performance", Social Behavior and Personality: An International Journal, vol. 37, p. 117-135.

LeRouge, C., Hevner, A.R. and Collins, R.W. (2007), "It's More than Just Use: An Exploration of Telemedicine Use Quality", Decision Support Systems, vol. 43, n4, p. 1287-1304.

Lapointe, L. and Rivard, S. (2005), "A Multilevel Model of Resistance to Information Technology Implementation", MIS Quarterly, vol. 29, n³, p. 461-491.

Livingstone L.P., Nelson D.L. Barr S.H. (1997), "Person-Environment Fit and Creativity: An Examination of Supply-Value and Demand-Ability Versions of Fit", Journal of Management, vol. 23, n², p. 119-146.

Lubart T. (2005), "How Can Computers Be Partners in the Creative Process: Classification and Commentary on the Special Issue", International Journal of Human-Computer Studies, vol. $63, n^{\circ} 4$, p. 365-369.

Lubart T. (2008), "Connecting Learning, Individual Differences and Creativity", Learning and Individual Differences, vol. $18, \mathrm{n}^{\circ} 4$, p. 361-362.

Lubart T. Guignard J.-H. (2004), "The Generality-Specificity of Creativity: A Multivariate Approach" in Creativity: From Potential to Realization, Sternberg, Grigorenko and Singer (Eds), American Psychological Association, Washington, DC, US, p. 43-56.

Lusch R.F. Nambisan S. (2015), "Service Innovation: A Service-Dominant Logic Perspective", MIS Quarterly, vol. 39, n 1, p. 155-175.

Lyytinen K., Yoo Y. Boland Jr R.J. (2016), "Digital Product Innovation within Four Classes of Innovation Networks", Information Systems Journal, vol. 26, n 1, p. 47-75.

Mahmoud-Jouini S.B., Fixson S.K. Boulet D. (2019), "Making Design Thinking Work: Adapting an Innovation Approach to Fit a Large Technology-Driven Firm", ResearchTechnology Management, vol. 62, n 5, p. 50-58.

Majchrzak A. Markus M.L. (2014), "Technology Affordances and Constraints Theory (of Mis) " in Encyclopedia of Management Theory, Kessler (Ed), Sage, Thousand Oaks, CA, p. 832836.

Malik M.A.R., Butt A.N. Choi J.N. (2015), "Rewards and Employee Creative Performance: Moderating Effects of Creative Self-Efficacy, Reward Importance, and Locus of Control", Journal of Organizational Behavior, vol. 36, p. 59-74.

Massetti B. (1996), "An Empirical Examination of the Value of Creativity Support Systems on Idea Generation", MIS Quarterly, vol. 20, n³, p. 83-97.

Merminod, V. and Rowe, F. (2012), "How Does PLM Technology Support Knowledge Transfer and Translation in New Product Development? Transparency and Boundary Spanners in an International Context", Information and Organization, vol. 22, n, p. 295 322.

Micheli P., Wilner S.J., Bhatti S.H., Mura M.Beverland M.B. (2019), "Doing Design Thinking: Conceptual Review, Synthesis, and Research Agenda", Journal of Product Innovation Management, vol. 36, n², p. 124-148. 
Mithas S. (2016), "Digital Intelligence: What Every Smart Manager Must Have for Success in an Information Age", Penguin UK.

Nagaraj, V., Berente, N., Lyytinen, K. and Gaskin, J. (2020), "Team Design Thinking, Product Innovativeness, and the Moderating Role of Problem Unfamiliarity", Journal of Product Innovation Management, vol. 37, $\mathrm{n}^{\circ} 4$, p. 297-323.

Nambisan S., Lyytinen K., Majchrzak A.Song M. (2017), "Digital Innovation Management: Reinventing Innovation Management Research in a Digital Work", MIS Quarterly, vol. 41, $\mathrm{n}^{\circ} 1$, p. 223-238.

Oldham G.R. Cummings A. (1996), "Employee Creativity: Personal and Contextual Factors at Work", Academy of Management Journal, vol. 39, n³, p. 607-634.

Orlikowski W.J. (2007), "Sociomaterial Practices: Exploring Technology at Work.", Organization Studies, vol. 28, n 9 , p. 1435-1448.

Osburn H.K. Mumford M.D. (2006), "Creativity and Planning: Training Interventions to Develop Creative Problem-Solving Skills", Creativity Research Journal, vol. 18, n², p. 173-190.

Overmyer T. Carlson E.B. (2019), "Literature Review: Design Thinking and Place", Journal of Business and Technical Communication, vol. 33, n ${ }^{\circ}$, p. 431-436.

Pacauskas D. Rajala R. (2017), "Information System Users' Creativity", Information Technology \& People, vol. 30, $\mathrm{n}^{\circ} 1$, p. 81-116.

Parnes S.J. Noller R.B. (1972), "Applied Creativity: The Creative Studies Project: Part Results of a Two Year Program", Journal of Creative Behavior, vol. 6, p. 164-186.

Petter S., Straub D.W.Rai A. (2008), "Specifying Formative Constructs in Information Systems Research", Management Information Systems Quarterly, vol. 31, n4, p. 623-656.

Pickering A. (2010), "The Mangle of Practice: Time, Agency, and Science" in University of Chicago Press, Chicago.

Plattner, H., Meinel, C. and Weinberg, U. (2009), "Design thinking" in Mi-Fachverlag, Landsberg am Lech.

Podsakoff P.M., MacKenzie S.B., Lee J.-Y. Podsakoff N.P. (2003), "Common Method Biases in Behavioral Research: A Critical Review of the Literature and Recommended Remedies", Journal of Applied Psychology, vol. 88, n5, p. 879-903.

Podsakoff P.M. Organ D.W. (1986), "Self-Reports in Organizational Research: Problems and Prospects", Journal of Management, vol. 12, n 4, p. 531-544.

Pope-Ruark R., Tham J., Moses J. Conner T. (2019), "Introduction to Special Issue: DesignThinking Approaches in Technical and Professional Communication", Journal of Business and Technical Communication, vol. 33, n 4 , p. 370-375.

Pozzi G., Pigni F. Vitari C. (2014), "Affordance theory in the is discipline: A review and synthesis of the Literature" in AMCIS 2014 Conference proceedings, Savannah, Georgia, USA,

Rauth I., Carlgren L. Elmquist M. (2014), "Making It Happen: Legitimizing Design Thinking in Large Organizations", Design Management Journal, vol. 9, n¹, p. 47-60.

Rahrovani, Y., Addas, S., Pinsonneault, A. (2014). "Exploring the Long Shadow of IT Innovation Adoption Decisions on IT Value. Systèmes d'Information et Management, vol. 19, n 4, p. 1-54.

Richard R., van der Pligt J.de Vries N.K. (1996), "Anticipated Affect and Behavioral Choice", Basic \& Applied Social Psychology, vol. 18, p. 111-129.

Ringle C.M., Wende S. Will S. (2005), "Smartpls 2.0 (M3) Beta", SmartPLS, Hamburg 2005.

Setia, P., Setia, P., Venkatesh, V. and Joglekar, S. (2013), "Leveraging digital technologies: How information quality leads to localized capabilities and customer service performance", MIS Quarterly, p. 565-590. 
Shirish, A. (2020), "Cognitive-Affective Appraisal of Technostressors by ICT-Based Mobile Workers and their Impacts on Technostrain", Human Systems Management, $\mathrm{n}^{\circ}$ Pre-press, $\mathrm{p}$. $1-21$.

Shirish A., Boughzala I. Srivastava S.C. (2016), "Adaptive Use of Social Networking Applications in Contemporary Organizations: Examining the Motivations of Gen Y Cohorts", International Journal of Information Management, vol. 36, nº 6, p. 1111-1123.

Srivastava S.C., Chandra S. (2018), "Social Presence in Virtual World Collaboration: An Uncertainty Reduction Perspective Using a Mixed Methods Approach", MIS Quarterly, vol. $42, n^{\circ} 3$, p. $779-804$.

Srivastava S.C., Chandra S. Shirish A. (2015), "Technostress Creators and Job Outcomes: Theorising the Moderating Influence of Personality Traits", Information Systems Journal, vol. $25, \mathrm{n}^{\circ} 4$, p. $355-401$.

Srivastava S.C., Mithas S. Jha B. (2013), "What Is Your Global Innovation Strategy?", IT Professional, vol. $15, \mathrm{n}^{\circ}$ 6, p. 2-6.

Srivastava, S.C. (2015), "Innovating for the future: charting the innovation agenda for firms in developing countries", Journal of Indian Business Research, vol. 7, n 4, p. 314-320.

Srivastava, S.C., Nehme, J.J., Luherne, A. Kone, B. (2021), "How Orange Achieved LongTerm Adaptability and Value Creation by Proactively Transforming its Business", MIS Quarterly Executive, vol. 20, n 1 , p. 6.

Srivastava S.C., Shainesh G. (2015), "Bridging the Service Divide through Digitally Enabled Service Innovations: Evidence from Indian Healthcare Service Providers", MIS Quarterly, vol. $39, \mathrm{n}^{\circ} 1$, p. $245-267$.

Srivastava S.C., Teo T.S.H. (2010), "E-Government, E-Business, and National Economic Performance", Communications of the Association for Information Systems, vol. 26, n¹, p. 267-286.

Srivastava S.C., Teo T.S.H. (2021), "Information System Quality Judgment for Continued Use of E-Government: Theorizing the Role of Positive and Negative Affect", Communications of the Association for Information Systems, (Forthcoming).

Stone M. (1974), "Cross-Validatory Choice and Assessment of Statistical Predictions", Journal of the Royal Statistical Society, vol. 36, n², p. 111-147.

Straub D., Boudreau M.-C.Gefen D. (2004), "Validation Guidelines for Is Positivist Research", Communications of the Association for Information Systems, vol. 13, p. 380-427.

Svahn F., Mathiassen L. Lindgren R. (2017), "Embracing Digital Innovation in Incumbent Firms: How Volvo Cars Managed Competing Concerns", MIS Quarterly, vol. 41, n¹,

Tarafdar M., Tu Q. Ragu-Nathan T.S. (2010), "Impact of Technostress on End-User Satisfaction and Performance", Journal of Management Information Systems, vol. 27, n³, p. 303-334.

Taylor, A. Greve, H.R. (2006), "Superman or the fantastic four? Knowledge Combination and Experience in Innovative Teams", Academy of Management Journal, vol. 49, n4, p. 723 740.

Thompson R.L., Higgins C.A. Howell J.M. (1991), "Personal Computing toward a Conceptual Model of Utilization ", MIS Quarterly. vol. 15, n¹, p. 125-136.

Tierney P. Farmer S.M. (2002), "Creative Self-Efficacy: Its Potential Antecedents and Relationship to Creative Performance", Academy of Management journal, vol. 45, $\mathrm{n}^{\circ} 6, \mathrm{p}$. 1137-1148.

Tierney P. Farmer S.M. (2011), "Creative Self-Efficacy Development and Creative Performance over Time", Journal of Applied Psychology, vol. 96, n², p. 277-293.

Unsworth K. (2001), "Unpacking Creativity", Academy of Management Review, vol. 26, n², p. 89-97.

Von Stamm B. (2008), "Managing Innovation, Design and Creativity", John Wiley \& Sons. 
von Thienen, J., Meinel, C., \& Nicolai, C. (2014). How design thinking tools help to solve wicked problems (Design thinking research (pp. 97-102). Springer.

Wang K. Nickerson J.V. (2017), "A Literature Review on Individual Creativity Support Systems", Computers in Human Behavior, vol. 74, p. 139-151.

Wang X., French B.F. Clay P.F. (2015), "Convergent and Discriminant Validity with Formative Measurement: A Mediator Perspective", Journal of Modern Applied Statistical Methods, vol. $14, \mathrm{n}^{\circ} 1$, p. 11 .

Wierenga B.van Bruggen G.H. (1998), "The Dependent Variable in Research into the Effects of Creativity Support Systems: Quality and.Quantity of Ideas", MIS Quarterly, vol. 22, n 1 , p. 81-87.

Withagena R. Kampb J.v.d. (2018), "An Ecological Approach to Creativity in Making", New Ideas in Psychology, vol. 49, p. 1-6.

Wold H. (1985), "Encyclopedia of Statistical Sciences", Partial least squares. Wiley, New York, p. 581-591.

Wolfe R.A. (1994), "Organizational Innovation: Review, Critique and Suggested Research Directions", Journal of Management Studies, vol. 31, n³, p. 405-431.

Woodman R.W., Sawyer J.E.Griffin R.W. (1993), "Toward a Theory of Organizational Creativity", Academy of Management Review, vol. 18, p. 293-321.

Yoo Y., Boland Jr R.J., Lyytinen K. Majchrzak A. (2012), "Organizing for Innovation in the Digitized World", Organization Science, vol. 23, n5, p. 1398-1408.

Yoo, Y., Henfridsson, O. and Lyytinen, K. (2010), "Research commentary-The New Organizing Logic of Digital Innovation: An Agenda for Information Systems Research", Information Systems Research, vol. 21, n 4, p. 724-735.

Zhang P. (2013), "The Affective Response Model: A Theoretical Framework of Affective Concepts and Their Relationships in the ICT Context", MIS Quarterly., vol. 37, n 1, p. 247 274.

\section{Appendices}

Appendix A: Contextual integration of digital innovation affordance and effective use of IS literature

\begin{tabular}{|c|c|c|c|c|c|c|}
\hline $\begin{array}{l}\text { Theoretical } \\
\text { Perspective }\end{array}$ & Context & $\begin{array}{l}\text { Innovation } \\
\text { Agent } \\
\text { Attributes }\end{array}$ & Technology & $\begin{array}{l}\text { Affordance } \\
\text { Potential }\end{array}$ & $\begin{array}{l}\text { Actualized } \\
\text { Innovation } \\
\text { Affordance }\end{array}$ & Outcomes \\
\hline $\begin{array}{l}\text { Digital } \\
\text { Innovation - } \\
\text { Exploitation } \\
\text { of existing } \\
\text { information } \\
\text { systems }\end{array}$ & $\begin{array}{l}\text { Need to } \\
\text { develop a } \\
\text { rough } \\
\text { prototype of a } \\
\text { digital } \\
\text { innovation } \\
\text { using design } \\
\text { thinking } \\
\text { creative } \\
\text { process }\end{array}$ & $\begin{array}{l}\text { Problem } \\
\text { solving } \\
\text { potential of } \\
\text { innovative } \\
\text { agent }\end{array}$ & $\begin{array}{l}\text { Access and } \\
\text { freedom } \\
\text { use }\end{array}$ & $\begin{array}{l}\text { ICT enabled } \\
\text { Creative } \\
\text { Process } \\
\text { Facilitation }\end{array}$ & $\begin{array}{l}\text { Actualized } \\
\text { Affordance }\end{array}$ & $\begin{array}{l}\text { Digital } \\
\text { Innovation }\end{array}$ \\
\hline $\begin{array}{l}\text { Effective Use } \\
\text { of IS }\end{array}$ & $\begin{array}{l}\text { A challenge } \\
\text { to propose a } \\
\text { solution to } \\
\text { any wicked } \\
\text { problem } \\
\text { (undefined) }\end{array}$ & $\begin{array}{l}\text { Context } \\
\text { specific } \\
\text { responsible } \\
\text { goal directed } \\
\text { IT user } \\
\text { attributes }\end{array}$ & $\begin{array}{lr}\text { Access and } \\
\text { freedom } \\
\text { use } \\
\text { existing } \\
\text { generic } \\
\text { institutional } \\
\end{array}$ & $\begin{array}{l}\text { ICT enabled } \\
\text { Creative } \\
\text { Process } \\
\text { Facilitation }\end{array}$ & $\begin{array}{l}\text { Effective } \\
\text { Use } \\
\text { Enactment - } \\
\text { The extent of } \\
\text { ICT enabled } \\
\text { design }\end{array}$ & $\begin{array}{l}\text { Direct } \\
\text { Outcome } \\
\text { (Measured): } \\
\text { Novel and } \\
\text { useful } \\
\text { solution }\end{array}$ \\
\hline
\end{tabular}




\begin{tabular}{|c|c|c|c|c|c|}
\hline & $\begin{array}{l}\text { faced by the } \\
\text { local } \\
\text { community } \\
\text { using ICTs } \\
\text { and design } \\
\text { thinking } \\
\text { creativity } \\
\text { method }\end{array}$ & $\begin{array}{l}\text {-Creative Self } \\
\text { efficacy } \\
\text {-Affect } \\
\text { Towards ICT } \\
\text { use }\end{array}$ & \begin{tabular}{|l|} 
and/or \\
personal ICT \\
tools for goal \\
achievement.
\end{tabular} & \begin{tabular}{|l|} 
thinking \\
creative \\
process \\
perceived by \\
specific goal \\
directed IS \\
users.
\end{tabular} & 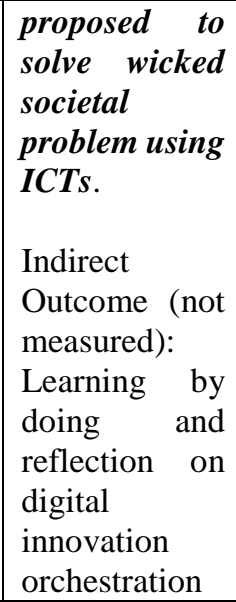 \\
\hline \multicolumn{6}{|c|}{$\begin{array}{l}\text { We situate the current research in digital innovation affordance and effective use of IS literature. The interaction } \\
\text { and the use of existing IT by a goal directed potential innovative agent for new purposes leads to enactment of } \\
\text { actualized affordance. Thus, both the agent attributes and the sociomaterial dimension constitute resources for } \\
\text { innovation orchestration. }\end{array}$} \\
\hline
\end{tabular}

\section{Appendix B: ICT Enabled Design Thinking (ICT-DT) creative process construct}

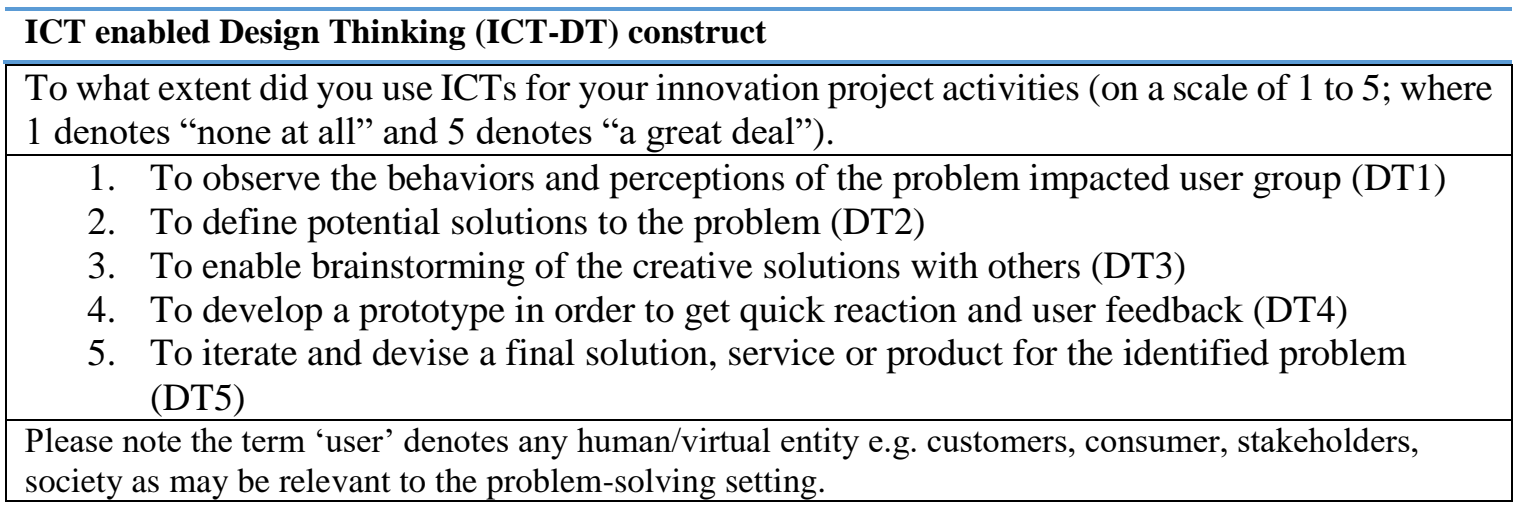

\section{Appendix C: Discriminant Validity Check for Formative Construct (ICT-DT)}

The methodological procedure for demonstrating discriminant validity for formative constructs is not the same as for models that have only reflective indicators. We followed a specific method proposed for structural equation models undertaken via SmartPLS. Per Wang et al., (2015) discriminant validity between formative causal constructs and reflective constructs can be established using the mediation method approach. In this case, each indicator of the ICT-DT construct was used as an independent variable and the 'digital innovation' construct was used as the dependent variable. If the path between the independent variables and the dependent variable is mediated by the formative causal construct ICTDT then one can conclude that there is sufficient discriminant validity between the formative construct (ICT-DT) and digital innovation. In our analysis, Path A refers to path coefficients of DT1-DT5 to ICTDT formative causal construct, Path B refers to the path coefficient of between ICT-DT to "digital innovation' and Path C refers to the path coefficient between individual indicators DT1-DT5 to 'digital innovation'. The below table proves the discriminant validity of the construct DT with regards to ICT enabled digital innovation, hence also ruling out any endogeneity issues that may arise. 


\begin{tabular}{|l|l|l|l|l|l|}
\hline & Path A & Path B & $\begin{array}{l}\text { Path C } \\
\text { without } \\
\text { controlling for } \\
\text { path A and B }\end{array}$ & $\begin{array}{l}\text { Path C } \\
\text { controlling for } \\
\text { path A and B }\end{array}$ & $\begin{array}{l}\text { Discriminant } \\
\text { Validity } \\
\text { through } \\
\text { mediation } \\
\text { (Partial or full) } \\
\text { Established }\end{array}$ \\
\hline DT1 & $.552^{*}$ & $.558^{*}$ & $.486^{*}$ & $.313^{*}$ & Yes \\
\hline DT2 & $.497^{*}$ & $.585^{*}$ & $.277^{*}$ & -.028 & Yes \\
\hline DT3 & $.524^{*}$ & $.544^{*}$ & $.476^{*}$ & $.261^{*}$ & Yes \\
\hline DT4 & $.558^{*}$ & $.579^{*}$ & $.307^{*}$ & -0.22 & Yes \\
\hline DT5 & $.565^{*}$ & $.545^{*}$ & $.404^{*}$ & .138 & Yes \\
\hline
\end{tabular}

\section{Appendix D: Full Collinearity Variance Inflation Test for Common Method Bias in SEM-PLS}

In addition to other procedures described in the manuscript, we conducted common method bias analysis in the context of PLS-SEM by employing "full collinearity variance inflation test". According to Kock (2015) for identifying common method bias using PLS, the inner VIF values for reflective and formative constructs can be utilized. Kock $(2015, \mathrm{p} 7)$ stated that "the occurrence of a VIF greater than 3.3 is proposed as an indication of pathological collinearity, and also as an indication that a model may be contaminated by common method bias. Therefore, if all VIFs resulting from a full collinearity test are equal to or lower than 3.3, the model can be considered free of common method bias." As per Kock 2015, a higher tolerance level of 5.0 is suggested for general collinearity tests, but the more stringent threshold of 3.3 is applied to test for common method bias.

Accordingly, we undertook the prescribed common method bias analysis and the VIF values for all the paths leading to the dependent variable were below 3.3. We also undertook the same test on all the main constructs used in the study in order to provide a full multicollinearity test, namely, with DT, CSEFF and AFFICT variables as well (Tables A to D). The results of the inner VIF values in all the cases were below 3.3 allaying the possibility of common method bias confounding our research results. See tables A to $\mathrm{D}$ below that provide the results of our analysis.

Table A. DINNOV Path

\begin{tabular}{|l|l|l|l|l|l|l|}
\hline & AFFICT & CSEFF & DINNOV & DT & GEN & PCOMP \\
\hline AFFICT & & & 1.166 & & & \\
\hline CSEFF & & & 1.122 & & & \\
\hline DINNOV & & & & & & \\
\hline DT & & & 1.235 & & & \\
\hline GEN & & & 1.045 & & & \\
\hline PCOMP & & & 1.177 & & & \\
\hline
\end{tabular}

Note: ATU- Affect towards Technology Use; CSEFF- Creative Self efficacy; DINV- Digital Innovation; DTICT enabled Design Thinking; GEN- Gender; PCOMP- Project Complexity

Table B: DT path

\begin{tabular}{|l|l|l|l|l|l|l|}
\hline & AFFICT & CSEFF & DINNOV & DT & GEN & PCOMP \\
\hline AFFICT & & & & 1.231 & & \\
\hline
\end{tabular}




\begin{tabular}{|l|l|l|l|l|l|l|}
\hline CSEFF & & & & 1.188 & & \\
\hline DINNOV & & & & 1.321 & & \\
\hline DT & & & & & & \\
\hline GEN & & & & 1.068 & & \\
\hline PCOMP & & & & 1.126 & & \\
\hline $\begin{array}{l}\text { Note: ATU- Affect towards Technology Use; CSEFF- Creative Self efficacy; DINV- Digital Innovation; DT- } \\
\text { ICT enabled Design Thinking; GEN- Gender; PCOMP- Project Complexity }\end{array}$ \\
\hline
\end{tabular}

Table C: CSEFF path

\begin{tabular}{|l|l|l|l|l|l|l|}
\hline & AFFICT & CSEFF & DINNOV & DT & GEN & PCOMP \\
\hline AFFICT & & 1.186 & & & & \\
\hline CSEFF & & & & & & \\
\hline DINNOV & & 1.344 & & & & \\
\hline DT & 1.163 & & & & \\
\hline GEN & 1.006 & & & & \\
\hline PCOMP & 1.114 & & & & \\
\hline $\begin{array}{l}\text { Note: ATU- Affect towards Technology Use; CSEFF- Creative Self efficacy; DINV- Digital Innovation; DT- } \\
\text { ICT enabled Design Thinking; GEN- Gender; PCOMP- Project Complexity }\end{array}$
\end{tabular}

Table D: AFFICT path

\begin{tabular}{|l|l|l|l|l|l|l|}
\hline & AFFICT & CSEFF & DINNOV & DT & GEN & PCOMP \\
\hline AFFICT & & & & & & \\
\hline CSEFF & 1.146 & & & & & \\
\hline DINNOV & 1.747 & & & & & \\
\hline DT & 1.682 & & & & & \\
\hline GEN & 1.059 & & & & & \\
\hline PCOMP & 1.143 & & & & & \\
\hline
\end{tabular}

